Florida International University FIU Digital Commons

3-15-2002

\title{
Florida's health care reimbursement for outpatient medical nutrition therapy
}

Katherine Marie Cabrera

Florida International University

DOI: $10.25148 /$ etd.FI14052521

Follow this and additional works at: https://digitalcommons.fiu.edu/etd

Part of the Dietetics and Clinical Nutrition Commons

\section{Recommended Citation}

Cabrera, Katherine Marie, "Florida's health care reimbursement for outpatient medical nutrition therapy" (2002). FIU Electronic Theses and Dissertations. 1957.

https://digitalcommons.fiu.edu/etd/1957

This work is brought to you for free and open access by the University Graduate School at FIU Digital Commons. It has been accepted for inclusion in FIU Electronic Theses and Dissertations by an authorized administrator of FIU Digital Commons. For more information, please contact dcc@fiu.edu. 


\section{FLORIDA INTERNATIONAL UNIVERSITY \\ Miami, Florida}

\section{FLORIDA'S HEALTH CARE REIMBURSEMENT FOR OUTPATIENT MEDICAL NUTRITION THERAPY}

A thesis submitted in partial fulfillment of the requirements for the degree of MASTER OF SCIENCE in DIETETICS AND NUTRITION

by

Katherine Marie Cabrera 
To: Dean Ronald M. Berkman

College of Health and Urban Affairs

This thesis, written by Katherine Marie Cabrera, and entitled Florida's Health Care Reimbursement for Outpatient Medical Nutrition Therapy, having been approved in respect to style and intellectual content, is referred to you for judgment.

We have read this thesis and recommend that it be approved.

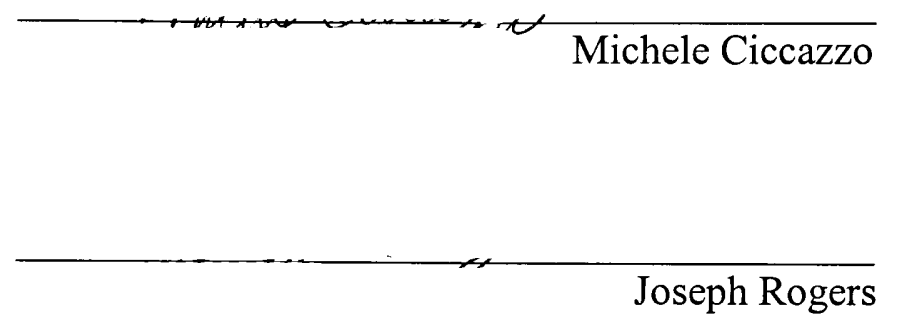

\section{Susan P. Himburg, Major Prøfessor}

Date of Defense: March 15, 2002

The thesis of Katherine Marie Cabrera is approved. 


\section{DEDICATION}

I dedicate this thesis to my family especially my daughter, Christine, who has renewed in me faith, hope, and love with a profound preservence for the future. May she always follow her dreams! And, to my husband Ed, who has stood by me throughout this endeavor. Without his computer and financial support I could not have finished this paper. 


\section{ACKNOWLEDGMENTS}

I would first like to thank Jesus Christ and His Mother Mary for the completion of this paper, because all blessings come from above.

Also, I want to thank my committee members, Dr. Susan P. Himburg, Dr.

Michele Ciccazzo and Joe Rogers for their time, patience and encouragement throughout the study.

A special thanks goes out to my church group, the community of St Edward Catholic Church, and my spiritual mentors Father Mitch, Noel and Father Mike for all their prayers and guidance. 


\title{
ABSTRACT OF THE THESIS
}

\section{FLORIDA'S HEALTH CARE REIMBURSEMENT FOR OUTPATIENT}

\section{MEDICAL NUTRITION THERAPY}

by

\author{
Katherine Marie Cabrera
}

Florida International University, 2002

\author{
Miami, Florida \\ Professor Susan P. Himburg, Major Professor
}

The purpose of this study was to describe and inform registered dietitians (RDs) in the State of Florida what insurance companies are providing in terms of medical nutrition therapy (MNT) coverage.

A questionnaire was developed to encompass major MNT reimbursement stipulations such as policies, specific diseases coverage, specific Current Procedural Terminology (CPT) codes and descriptors, use of the medical necessity letter and nutrition cost benefits analysis (CBA). The questionnaire, encompassing 27 plans (HMO, PPO, Indemnity, Medicare, Medicaid), also served as a MNT promotional tool for 11 top administrators from insurance companies (10 private, 1 government) around the State of Florida. The results showed that $78 \%$ of all plans reimbursed for MNT caseby-case even without specific MNT policies. Sixty-seven percent of the plans would approve for MNT reimbursement with a medical necessity letter. Half of these top administrators showed an optimistic interest in using nutrition CBAs, case studies and practice protocols for creating MNT policies. The top ranked CPT codes were found to be 99204 (1), 99202 (2), 99201 (2), 99203 (3). The most recognized corresponding descriptors with the CPT were MNT, disease management skills and training and nutritional counseling.

This questionnaire may be used to create additional MNT reimbursement audits or research. The results given in this study can aid RDs in proper documentation on 
insurance claim forms, usage of the medical necessity letter, nutrition CBAs, practice guidelines and case studies for successful MNT reimbursement. 
I. INTRODUCTION

Purpose

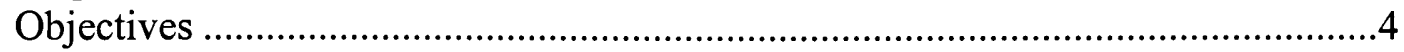

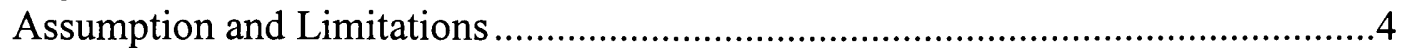

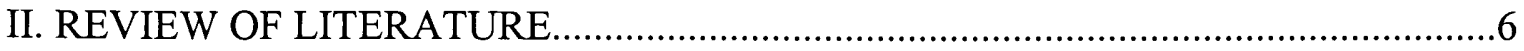

Evolution of the Health Insurance Industry ....................................................6

Establishment of MNT Reimbursement Policies.................................................

Documentation Factors that Increase MNT Reimbursement................................11

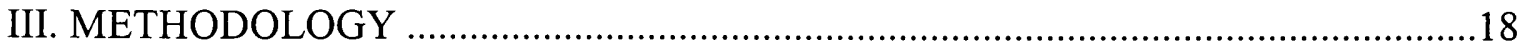

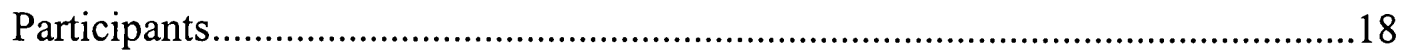

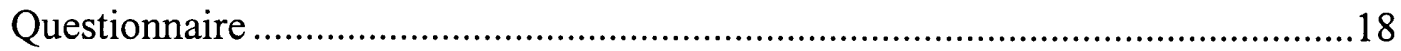

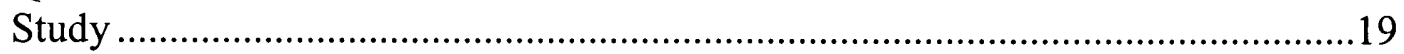

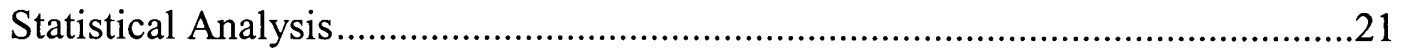

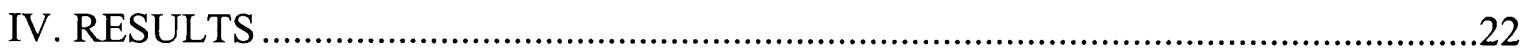

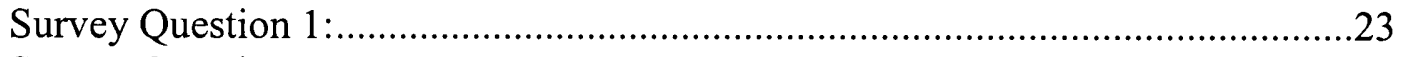

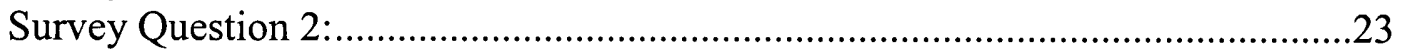

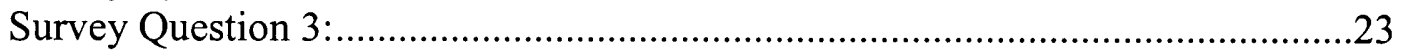

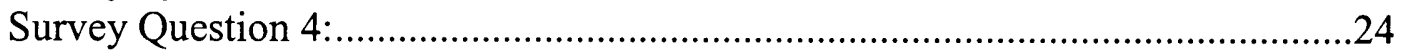

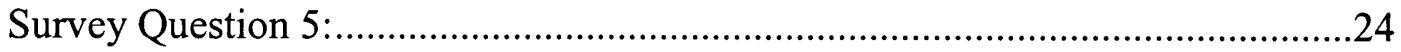

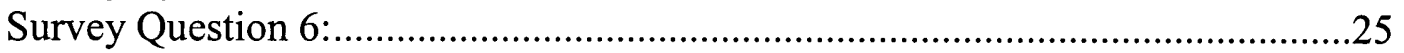

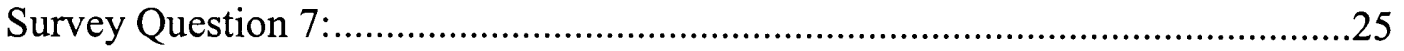

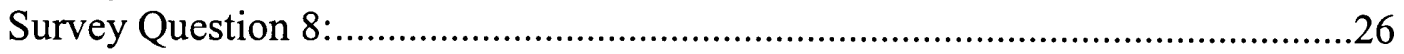

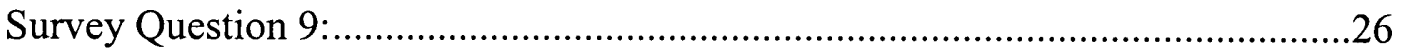

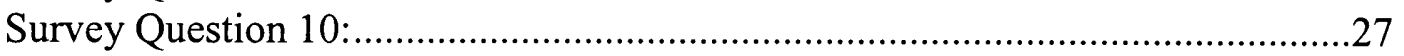

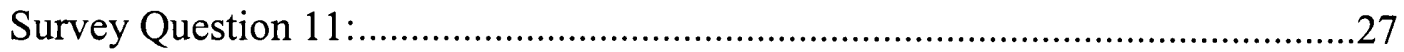

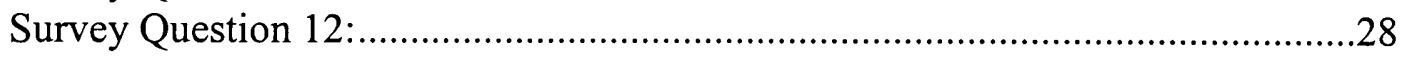

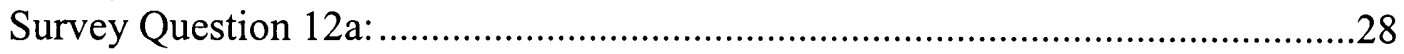

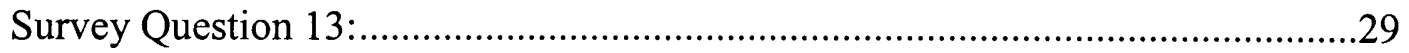

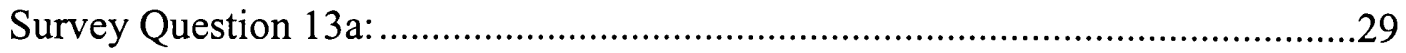

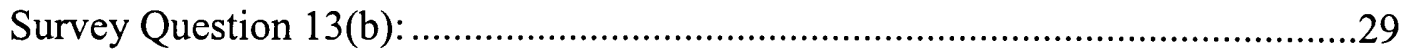

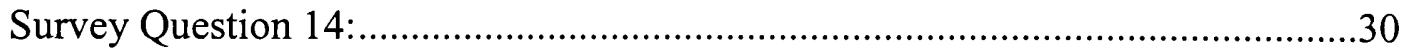

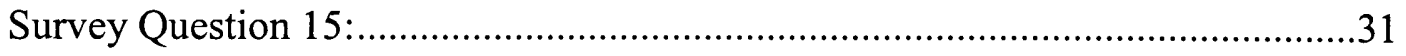

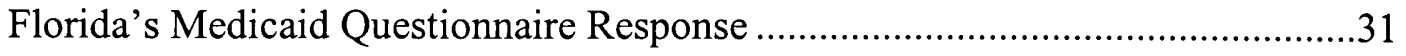

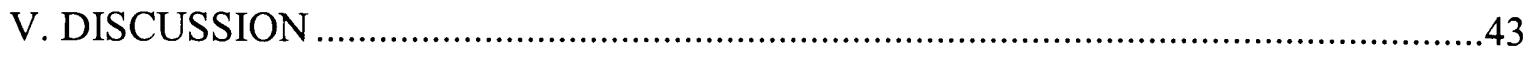

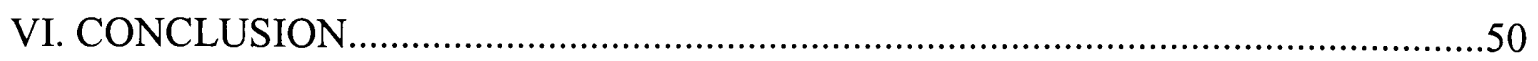

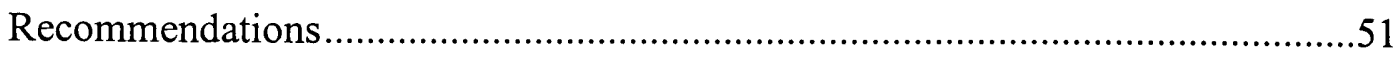

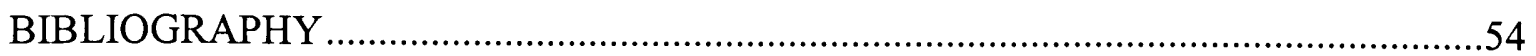

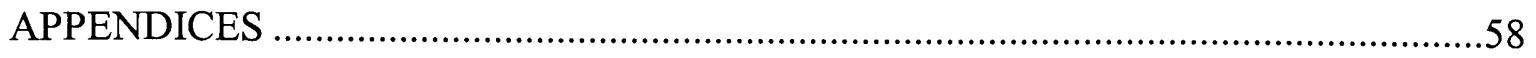




\section{LIST OF TABLES}

TABLE

PAGE

1. Plans offered by the surveyed insurance companies.

2. Participant's ability to make decisions for MNT reimbursement.

3. The professional titles of the participants

4. Carriers providing Registered Dietitians.

5. Do Florida's carriers have a MNT reimbursement policy?

6. MNT policies.

7. Are Florida's carriers reimbursing for outpatient MNT case-by-case?

8. Department for claims or preauthorization.

9. Who are the case reviewers?

10. Do carriers reimburse for specific disease over other diseases for MNT?

11. Ranking of disease States that are more often reimbursed for MNT. .38

12. CPT codes accepted for MNT

12a. CPT descriptors frequently accepted for MNT.

13. Does a medical necessity letter influence the rate of reimbursement?

13a. The acceptance rate of a medical necessity letter with an ICD-9 code and

Registered Dietitian signature.

13b. The influence of licensure, MS, or Ph.D on the acceptance of MNT

Reimbursement.

14. Carrier's use of MNT outcome documentation.

15. Carrier's interest in MNT outcome documentation.

16. Florida Agency for Health Care Administration Questionnaire. 


\section{CHAPTER I}

\section{INTRODUCTION}

Third party reimbursement is a vital key for accessing valuable dietetic services in the outpatient setting. Lack of a federal government mandated Medical Nutrition Therapy (MNT) policy has hindered third party reimbursement for Registered Dietitians (RDs) in the outpatient setting. In the 1960s the federal government established Medicare (1965) and Medicaid (1966) programs (1-3). These programs provide hospital and medical insurance to a defined population of need in America. Medicare and Medicaid influence state and private insurance companies' reimbursement policies that give medical care under their provisions.

MNT benefits were not established under Medicare and Medicaid in these early years. Without the American Dietetic Association's (ADA) political voice, policy makers were not knowledgeable about the importance of nutrition in health care (3). For three decades the public, both low-income and privately insured, have had limited access to medical nutrition therapy.

The ADA has made many strides in the political arena in recent years and continues to fight for universal MNT coverage. Since 1992 ADA has focused its efforts on obtaining federal reimbursement for MNT benefits and has established a Health Care Reform Team, Political Action Committee (PAC), Nutrition Services Payment System project (NSPS), and the Reimbursement Team (1-12). Targeting key legislative members ADA's Health Care Reform Team promotes MNT by emphasizing the cost effectiveness of medical and disease management and preventive treatments $(3,7)$. ADA's Health Care Reform Team's efforts produced the Medicare MNT Act of 1997 (H.R. 1375/S.597) (12). 
Published in 1999, the National Academy's report by the Institute of Medicine (IOM), The Role of Nutrition in Maintaining Health in the Nation's Elderly: Evaluation

Coverage of Nutrition Services for the Medicare Population helped ADA gain momentum in Congress for the passage of this Act in December of 2000 (13-16). The passage of the Medicare MNT Act provided ADA a major victory in obtaining Medicare provider status for nutrition services for diabetes and renal disease.

The Medical Nutrition Therapy Amendment Act of 2001, drafted by ADA, would add other nutrition services for nutrition related diseases (i.e. cardiovascular diseases) and was introduced to Congress in 2001. Additionally, there is bipartisan congressional support for a new Medicare Wellness Act, which would establish MNT for cardiovascular diseases. ADA's marketing strategies and commitment in the legislative arena have positively influenced key political lawmakers and have resulted in opportunities for MNT reimbursement at federal and state levels as well as with private insurance companies.

Models of some state Medicaid plans and private health insurance company plans are based on Medicare (1-3). However, how private insurance companies interpret government policies still may cause inconsistencies in the health care insurance industry for MNT reimbursement and may lead to extreme variances between states for MNT coverage.

The ADA is accomplishing the fight for MNT coverage on the state level through state dietetic associations. ADA created a MNT reimbursement network through the Nutrition Service Payment System (NSPS) in each state's dietetic association. NSPS representatives provide a valuable education and resource to dietitians on MNT 
reimbursement $(1,2,4,5)$. NSPS representatives serve as a link between ADA's reimbursement team and RDs on the state level.

State dietetic associations have been working towards MNT reimbursement. Using cost benefit analysis (CBA) to cite the benefits of MNT. The Florida Dietetic Association (FDA) is currently attempting to influence our state insurance agencies and Publix Supermarkets, a private provider, to add MNT benefits to their insurance packages. Using similar CBAs strategies in the past, FDA was successful in influencing Florida's Agency for Health Care Administration, which regulates Medicaid, to cover Dietitian's services under the Developmental Services and Aged and Disabled Adult waiver (17). Other states have also been successful in obtaining MNT reimbursement from Medicaid and private insurance using CBA (18-34).

The dietetic profession provides cost effective health care needed in the outpatient areas (22-42). Managed care organizations and the federal government are looking at alternative treatments best accomplished in the outpatient or private practice area as a means to decrease the high cost of health care (35). Coverage would give the financial solvency that is needed for our profession to grow in the outpatient setting, but is our profession ready to accept the challenge of continually moving forward in the health insurance industry in each state? The challenge is for RDs to stay informed on government and private insurance companies' reimbursement policies for MNT. The results of this study provide reimbursement information, which can be used by individual RDs in seeking MNT coverage. In turn this can increase patient access to MNT. 


\section{Purpose}

Knowledge of reimbursement criteria used by the insurance industry is the cornerstone of the financial growth needed for advancements in the health care industry. The purpose of this study was to provide RDs with an overview of Medical Nutrition Therapy (MNT) reimbursement criteria used for outpatient settings in Florida.

\section{$\underline{\text { Objectives }}$}

1) Determine policies and coding practices for outpatient MNT reimbursement by Florida's top 25\% insurance companies.

2) Determine medical diagnoses or conditions which are the most frequently reimbursed for MNT.

3) Assess MNT cost benefit analyses, outcome documentation, and practice guidelines usage in Florida's insurance industry.

4) Assess the impact of the medical necessity letter and registered dietitian credentials on MNT reimbursement.

\section{$\underline{\text { Assumption and Limitations }}$}

This study was based on the following assumption: Targeted participants in the study were Chief Medical Officers (CMO) or top-level directors or managers of the insurance company. Some CMOs will delegate the questionnaire to other directors or managers of specific departments for the MNT criteria information. 
Extraneous factors:
A) Unbiased recording and interpreting response to open-ended questions.
B) Participants' indirectly receiving questionnaire by fax or envelope.
C) Poor response rate due to time limitation of the participants.
D) Participants' lack of knowledge of RDs and MNT.
E) Insurance companies' policies for participating in surveys. 


\section{CHAPTER II}

\section{REVIEW OF LITERATURE}

\section{Evolution of the Health Insurance Industry}

Coverage or third party payment is when the insurance company pays a percentage of the enrollee's medical bills. The high cost of medical care in the 1930s created the first insurance plan in a university setting. Private insurance companies followed by adding health plans to their coverage.

The US government initiated its involvement with the health care industry in the 1960s by establishing Medicare and Medicaid. Medicare provides medical care to an elderly population, patients with kidney disease and with other disabilities. Medicare has two parts: Part A deals with hospital inpatient, nursing home facilities and hospice coverage; and part B covers health services, medical equipment and supplies in the outpatient setting. In the past, outpatient MNT was covered only if prescribed and supervised by a physician (1-3). Due to the recent passage of the Medicare MNT Act, RDs can become providers of nutrition services for diabetic and kidney disease patients and receive payment through Medicare part B (14).

Medicaid provides medical insurance to the poor, disabled and working poor. Medical services vary from state to state. This is due to each state's opportunity to develop eligibility, coverage policies and payment schedules, subject to federal standards and guidelines. In the past, nutrition services covered by Medicaid included those for pregnant women and children. Now "Section 1500 waivers" from the federal government give some states, including Florida, the opportunity to add more nutrition services under Medicaid (18-20). This makes it possible for RDs to obtain payment 
through the Medicaid program. Dietitians' services in Florida are covered under the Developmental Services and Aged and Disabled Adult waiver.

As health care costs have increased through the years, the private insurance industry has evolved from the traditional fee for service model to predominantly Managed Care Organizations (MCOs)(36,37). The traditional health care coverage was a fee for service plan, where there was no monitoring system for the health care versus cost. MCOs provide business services to physician groups as well as aiding in controlling cost for the patient and physician. MCOs emphasize preventive and cost effective health care. Their ultimate goal is to obtain the most cost efficient medical care for the patient.

Two examples of MCOs are Health Maintenance Organizations (HMOs) and Preferred Provider Organizations (PPOs) $(1,2,36)$. HMOs are insurance plans that emphasize preventive care through controlled medical care access and cost through a designated gatekeeper, the Primary Care Physician (PCP). It is feasible for the PCP to keep the patient healthy and away from high cost medical procedures. This is an incentive for the PCP to use disease management or preventive medicine in the outpatient setting to lower costs $(36,37)$. A less restrictive plan is the PPO. PPOs are a network of physicians from which members can choose, and pay a discounted fee-for-service.

Recently the complementary/alternative medicine (CAM) plan has been created to meet the demands for preventive and disease management health care. These specialized insurance networks provide access to non-physician providers who offer alternative services (38). These plans, initiated after the implementation of this study, provide another viable avenue for $\mathrm{RDs}$ to receive MNT coverage. 


\section{Establishment of MNT Reimbursement Policies}

Medical nutrition therapy (MNT) is the term used to describe the services provided to clients by Registered Dietitians. MNT includes an in-depth nutrition assessment followed by counseling and education for diet modifications. Specialized nutrition therapies such as tube feedings are also included in MNT (34). The dietetic profession has recognized the need to receive reimbursement for their services. Reimbursement provides the necessary revenue to keep or expand MNT services in the health care environment. As the health insurance industry grows the dietetic profession can integrate their services with the insurance industries' cost containing strategies.

Dietitians are successfully marketing MNT services as a vital link between quality health care and cost on the federal, state, and private health insurance levels $(11,16,17,22,23,28)$. Anderson et al $(23)$ showed that effective MNT marketing to federal government and private health insurance companies creates MNT reimbursement. This article describes how the North Dakota Dietetic Association (NDDA) received standardized outpatient MNT reimbursement policies from Medicaid and Blue Cross Blue Shield of North Dakota (BCBSND).

NDDA's priority for the establishment of MNT reimbursement was the creation of the Health Task Force committee. NDDA's committee was made up of Nutrition Service Payment System chairpersons, Legislative Network coordinators, the NDDA's president, the president-elect, past presidents, Clinical Practice Groups' representatives media representatives, alliance coordinators, and several State dietetic association members. These committee members met with the State Health Task Force for the 
establishment of North Dakota's own basic benefit package. This enabled NDDA's members to create an alliance with Medicaid and Blue Cross Blue Shield policy makers.

A formal presentation was warranted by Blue Cross Blue Shield to discuss medical nutrition therapy with NDDA members. The portfolio consisted of RDs' qualifications: education requirements, role and scope, licensure requirements and Code of Ethics, practice guidelines, and typical charges and numbers of visits for specific diagnoses around the state. North Dakota's BCBS vice president and department representatives agreed to reimburse for outpatient MNT services and allowed RDs to become providers through an application process. Medicaid policy makers also established MNT outpatient reimbursement.

Overall three elements were key for the MNT reimbursement policy success. The first was to demonstrate the cost effectiveness of MNT, secondly was to communicate and network with policy makers and thirdly to bargain for uniform benefits for all dietitians in the state.

The cost effectiveness analysis provided NDDA proof that MNT is associated with a positive medical or financial outcome (23). The term Cost Benefit Analysis (CBA) is the universal term that encompasses both cost benefit and cost effectiveness analysis (CEA) (34). CBA establishes a ratio of benefits to the cost of the program. CEA expresses MNT outcome as cost per unit of result. These are tools for the RD to market services to the government or private health insurance industry. ADA has been proactive in documenting the economic benefits of MNT services (29-41).

One study by Weese et al (42) describes how dietitians at the Ohio State University Hospital successfully obtained a reimbursement plan for the outpatient 
nutrition clinic through the self-insured program called "The Ohio State University Health Plan". One of the key factors was the inclusion of a CBA that showed pharmaceutical cost savings for a diabetic patient receiving MNT. It was concluded that administrators approved the MNT proposal based on the CBA and cost-containment strategies.

Also, in a study done by Hassell et al (43) one of the reasons for little reimbursement for nutrition services was economics. Many of the insurance companies did not utilize nutrition services for disease prevention. This article stressed how dietitians need to produce and market CBA and CEA to justify their value from the prospective third party payers. They also recommended additional MNT reimbursement surveys including questions concerning insurance companies' usage of CBA data for reimbursement of nutrition services.

Besides financial documentation, NDDA influenced policy makers with practice guidelines (22). NDDA created practice guidelines that explained the scope of care given by the RD. ADA has followed NDDA by creating Medical Nutrition Therapy Across The Continuum of Care manuals (27). Massachusetts Dietetic Association (MDA) used these client protocols to develop MNT policies for Blue Cross for Blue Shield (BCBS) of Massachusetts (28). Both the practice guidelines and the client protocols were developed to specifically explain health care provided by RDs and the projected outcomes. Both were developed to help the insurance companies understand the scope of care given by MNT. In turn, both were used to establish MNT policies for BCBS.

In addition, NDDA included and licensure requirements in the successful portfolio presented to BCBSND. A study by Baranoski et al (44) shows that 43 insurance 
companies (52.4\%) around the USA were reimbursing for MNT. The majority $80 \%$ of insurance companies surveyed required licensure for reimbursement. From this Baranoski et al (44) concluded that licensure played an important role in the creation of MNT policies

Also, documentation of actual MNT reimbursement can influence hospital administrators', financial backers' or insurance companies' decisions to establish nutrition policies for the outpatient setting. A study completed by Fatzinger et al (45) obtained reimbursement trends for outpatient dietitian services at Sinai Hospital in Baltimore, Maryland. An evaluation of 158 outpatients' bills during a 3-month period showed a high reimbursement rate. Of those that were reimbursed, $65 \%$ received $80 \%$ of the charge. Fatzinger et al (45) concluded that analysis of reimbursement provides proof that existing programs are solvent. This information can be used to support proposals for new programs, or contracting with insurance companies for reimbursement services.

These above studies show many different ways RDs can justify the establishment of MNT policies.

\section{Documentation Factors that Increase MNT Reimbursement}

1500 HCFA Form and Codes: Documentation of MNT service through a 1500 HCFA superbill or medical necessity letter can influence MNT coverage. Proper documentation on the insurance claim form will increase reimbursement $(35,42,43,45$, 47-53). Coding is a vital part of the documentation process on claim forms. Appropriate insurance nomenclature such as diagnosis codes (ICD-9-CM), description of treatment (CPT codes by the AMA) and descriptors on the Health Insurance Claim Form (e.g. Superbill, HCFA 1500) create the appropriate avenue for successful reimbursement. The 
medical diagnosis, procedures, and descriptors are assigned specific codes $(52,53)$. The International Classification of Disease, 9th Revision Clinical Modification (ICD-9-CM) is the medical diagnosis assigned by the physician. Current Procedural Terminology (CPT) of the American Medical Association (AMA) is a listing of the descriptor codes for the physician's procedures and services (1). CPT is a standard five-digit number, but the corresponding descriptors can vary. The most common and important coding system for nutrition services by RDs in the outpatient setting is the CPT. RDs who use CPT have a better chance of reimbursement due to the insurance companies' familiarly with the system because of the frequent use of this system with physicians (52).

The AMA and the Center for Medicare and Medicaid Services (CMS) formerly called the Health Care Financing Administration have approved three new CPT codes for MNT $(14,16,56)$. These are the only specific CPT codes and descriptors for MNT. Registered Dietitians can use other CPT codes but reimbursement may not occur. The three new codes for MNT are the following:

1. 97802 - initial assessment and problem solving, individual nutrition counseling, 15 minute per session.

2. 97803 - follow up individual nutrition counseling, for 15 minute per session.

3. 97804 - group nutrition education or counseling for 30 minute per session. These codes will allow Registered Dietitians provider status and reimbursement for Medicare diabetic and kidney disease patients. These codes were developed after the implementation of the present study. 
Also, some insurance companies have designated CPT codes for MNT, but could vary from state to state $(52,53)$. Blue Cross Blue Shield of North Dakota made specifications for MNT reimbursement with participating dietitians (23). MNT reimbursement is contingent upon physician referral, CPT codes, and ICD-9 coding established by BCBS, and proper filing of the HCFA-1500 claim form. BCBS provided participating RDs education on proper use of BCBS claim forms and code numbers. BCBS has provided specifications to participating RDs on medical diagnoses, corresponding codes, and the number of allowed visits. The requirements for North Dakota's Medicaid MNT reimbursement were the use of HCFA-1500 forms with given procedure codes.

In their study conducted in Maryland, Fatiznger et al (45) found that the procedures or code used to fill out the insurance claim form aided in obtaining reimbursement. The codes used were Annotated Codes of Maryland. The corresponding descriptors were "nutrition visits," which is "billing incident to a physician's professional services." It was shown from past studies that medical necessity determined by a physician's code and corresponding descriptor was important when filing a claim.

Medical Necessity: In a two-phase study conducted by Bolonda et al (46) clients from a nutrition clinic at the Los Robles Regional Medical Center were surveyed to determine submission rates and reimbursement rates. All the clients in the study received outpatient nutritional counseling. In the first phase, 191 clients were given a questionnaire five months after the nutrition session. This retrospective survey showed that of the $60 \%$ that responded only $65 \%$ submitted the form and only $15 \%$ received reimbursement. Evaluation of these results led to the second phase. 
In the second phase, 76 clients received education on how to file a claim along with a letter of medical necessity. A telephone survey was conducted five weeks after the session. Results showed that of the $88 \%$ who responded, $70 \%$ submitted a claim and $42 \%$ received reimbursement. Since there was no difference in the submission rate between the two phases the authors concluded that education on filing a claim was not necessary. The reimbursement rate improved in phase II with the submission of the letter of medical necessity. The clinic increased the reimbursement rate by submitting the claim with the attached medical necessity letter for the client.

These letters of medical necessity explained the nutritional care plans and anticipated outcome of the patient, along with the physician's signature. The overall recommendation was that it is necessary to submit the appropriate documentation and a medical necessity letter with the insurance claim to increase chances for reimbursement. This suggests that appropriate communication to the insurance company through the medical letter was the factor that increased the reimbursement.

Medical necessity can be measured by the actual disease state on the claim form at the insurance company. Results of a study done by Gould et al (50) showed that there was a ranking system for medical diagnosis and conditions used by insurance companies. They conducted a telephone survey to 97 insurance companies that reimbursed the Maternal and Child Health programs in Utah. The results showed that of the $52 \%$ who responded, $23 \%$ were reimbursed for nutrition services depending on medical necessity, physician prescription, and type of policy. Also, 29\% stated that provision for nutrition services varied with the medical necessity. 
A study by Rood and Griffith (54) used a telephone survey for 325 insurance companies that conducted business in a three-district area of Ohio. Half of the respondents stated medical necessity as the primary criteria for reimbursement. Some medical diagnoses were more likely to be reimbursed than others. Results showed that nutrition services such as dietary instruction and nutrition assessment were more readily reimbursed for diabetes, cardiovascular disease, hypertension, and malnutrition. These medical diagnoses had a higher rate of reimbursement than obesity.

According to a study in 1996, Blue Cross Blue Shield of North Dakota reimbursed for MNT for all forms of diabetes, cardiovascular and pre-end stage renal disease in the outpatient setting. Anderson et al showed that North Dakota's Medicaid reimbursed MNT only for diabetes, cardiovascular conditions, and a range of eating disorders (23).

Fatiznger et al (45) found the top diseases reimbursed were diabetes, hyperlipidemia, and hypertension. Obesity was rejected due to Maryland's code regulations.

Hassell et al's (43) analyzed MNT reimbursement policies, specific nutrition services and disease conditions and concluded that documentation of medical necessity and cost effectiveness were important factors for MNT reimbursement. Half of the insurance companies studied covered nutrition services if medical necessity was communicated effectively. The top diseases covered were diabetes and morbid obesity. Diagnoses that were not covered as frequently included renal disease, gallbladder, malnutrition, and inflammatory bowel disease. 
In a study by Bell et al reimbursement to clients receiving outpatient nutrition services was reported for only $17 \%$ (49). For this study, hospital and private practice dietitians tallied their clients' reimbursement rates. The primary reason cited by the insurance companies for denying nutrition services was that dietitians were not a covered provider. The top two medical diagnoses for the $17 \%$ who received reimbursement were diabetes and gestational diabetes.

These studies showed that documenting medical necessity was a major factor associated with reimbursement. Both Gould et al (50) and Bolonda et al (46) showed that medical necessity documented by a medical necessity or outcome documentation letter and proper coding on claim forms resulted in improved reimbursement rates.

Education and Government Credentials: How influential is the RD's professional registration and licensure credentials on claim forms or medical necessity letters. The medical professional that provides Medical Nutrition Therapy is the Registered Dietitian (RDs). The credentialing agency, the Commission on Dietetic Registration (CDR), requires that RDs have at least a Bachelor's degree from an accredited US university, complete a supervised field experience, and pass the Registration Examination for Dietitians. The American Dietetic Association (ADA) has a code of ethics and the CDR has regulations to monitor RDs. Licensed RDs are monitored by their State's regulations on education and conduct $(1,2)$.

Can RDs' credentials and licensure titles influence MNT reimbursement when signing a medical necessity letter or claim? The ADA and the CDR take great efforts to ensure the highest quality care from our profession. Baranoski et al (44) found that the insurance companies who provided MNT reimbursement also had a high percentage 
requiring licensure. However, Rood et al (54), found that insurers were unaware that RDs were licensed in their state. Assessing the current status of this area's importance will allow RDs continued support for professional growth and recognition in the insurance industry.

Currently, a majority of private insurance companies and the federal government are beginning to create reimbursement policies specific to nutrition services (14, $38,44,46,50,56)$. RDs must learn the keys in obtaining reimbursement until more MNT policies are established at the state and federal level. More MNT reimbursement will occur when RDs understand the insurance process and market MNT health care benefits. An important link for RDs is to stay informed of MNT reimbursement through continued research on insurance criteria for MNT reimbursement. 


\section{CHAPTER III \\ METHODOLOGY}

\section{Participants}

The participants in this survey were Chief Medical Officers (CMOs) from health insurance companies (HMOs, PPOs and Indemnity) around the State of Florida. They were chosen from Florida Trend's “1998 Annual TopRank Florida The Only Statewide Book Of Lists" (57). In addition to the CMOs' listing, the magazine provided names of the insurance companies, addresses, phone numbers, and ranking by enrollment.

The decision to target CMOs as the respondents for this study was based on their medical and insurance knowledge, as well as their administrative power. There were two other participants who weren't CMOs that participated in the survey. One CMO recommended a nurse to complete the questionnaire. Also, the Program Administrator for the Agency For Health Care Administration for the State of Florida was contacted and agreed to complete the survey in Phase I.

\section{Questionnaire}

A questionnaire to collect data on essential parts of the reimbursement process for MNT was developed for the study (Appendix A). The questionnaire was produced by the researcher through an accumulation of research studies, and approval of the thesis committee $(2,42,43,46,49,50,52,54)$. The first part of the survey (Questions $1-8)$ was structured to determine if the insurance company had any policies or procedures for MNT reimbursement or whether MNT reimbursement was done case-by-case basis. The title and position of the person responsible for decisions regarding outpatient MNT reimbursement was identified. 
Questions 9-12 dealt with the documentation of medical necessity, IC9 codes, maximum benefits and CPT codes, and CPT description of services. Question 12 analyzed the importance of the medical letter in the reimbursement process. Two additional factors of the medical necessity letter were also analyzed for their role in obtaining MNT reimbursement. One looked at whether it was acceptable to have a Registered Dietitian's signature with just an ICD-9 code, and no MD signature on the letter. The other looked at the impact the RDs signature plus his/ her education and government credentials on MNT reimbursement.

The last two questions $(13,14)$ dealt with evaluation of the usage of MNT outcome documentation, CBA, case studies and/or practice guidelines on the MNT reimbursement process by these insurance companies.

\section{$\underline{\text { Study }}$}

The survey period was January 1999 through August 2000 and consisted of two phases. Twenty-three insurance companies were contacted in Phase I and 21 in Phase II.

Phase I was a test period for the survey's question and response rate. Initially the researcher attempted to reach the CMOs of 23 companies. All of the contacted CMOs were unavailable and their assistants each requested that the survey to be faxed. Therefore what was to be a telephone survey was changed to a survey faxed to the CMOs. A personalized cover letter accompanied the fax explaining the reason for the survey, along with the return fax number (Appendix B). Each company was faxed one survey for each plan (HMO, PPO, Indemnity) that company provided to its members from January 1999-May 1999. Only two surveys were returned by fax stating they were not insurance providers. One was returned by mail from the Florida Health Care 
Administration. First they called the researcher and then mailed back the survey. Three months after the initial fax was sent a reminder letter (Appendix C) was faxed to 12 companies that did not respond. The reminders were stopped at twelve due to a time deadline with the student's coursework and concerns for effectiveness of the questionnaire. The researcher's time and efforts went to save the questionnaire and study.

During May 1999 to August 1999 the researcher worked to identify possible areas that could influence participation from the CMOs. Two different areas were identified on which to focus in order to increase participation.

The first area was to condense the questionnaire. In Phase I one survey was sent for each health plan. The survey was changed to include a checklist of possible health plans including Medicare and Medicaid after the questions. The questionnaire used in Phase II had all the plans on one survey. Medicare and Medicaid were also added due to the variety of plans offered by the insurance companies.

The second area of focus was the mode of delivery of the survey. The survey in Phase I was transmitted by fax to the CMO's assistant. Phase II surveys were change delivered by Federal Express directly to the CMOs.

Prior to the initiation of a Phase II, the list of insurance companies identified in Phase I was updated. Each insurance company was called to update telephone numbers, addresses, and new assistants and CMOs. All companies were sent an explanation cover letter (Appendix A). For Phase II the actual sending and receiving of the revised survey to 21 insurance companies by Federal Express took place from August 1999 to August 
2000. A follow up mailing, which included another cover letter and another copy of the survey, and a phone call to the assistants, occurred three months after the initial mailing.

\section{$\underline{\text { Statistical Analysis }}$}

The purpose of the study was to determine criteria for reimbursement for outpatient MNT. This was a descriptive type study with nominal (qualitative) and ordinal (ranking) data. The results are reported as variable frequency counts, percentages, means, and rank order count. The written answer questions were analyzed qualitatively. 


\section{CHAPTER IV}

\section{RESULTS}

\section{Participants from Florida's Top 25\% Insurance Companies}

The results reported here are from questionnaires sent to 21 insurance companies in Phase II representing the top $25 \%$ based of the number of insurance companies in the State of Florida. There were 10 of the 21 (48\%) insurance companies that responded. Nine of the $10(90 \%)$ were private companies actually completed the questionnaire. One of the insurance companies only sent back the cover letter, stating that they were made up of numerous PPO's that make their own decisions regarding the items on the questionnaire. From the nine private companies, a total of 27 plans were represented due to the different plans offered at each company (Table 1).

Although there is a small sample size, the companies with HMO plans 9 of the 9 $(100 \%)$ that completed the questionnaire represent $63 \%$ of the enrollees from the top $25 \%$ HMO insurance companies for the State of Florida. For those that did respond, their rankings, name of company and their HMO plan enrollment, in parenthesis, are listed below: 1 Health Options Inc: Blue Cross Blue Shield's HMO division $(663,684), 3$ Prudential (548,935), 4 Humana (520,355), 5 Cigna (397,463), 7 Foundation (190,000), 8 HIP Health Care (140,823), 15 Principal (51,311), 16 Florida Health Plan $(49,212)$, and 20 Jackson Memorial Hospital (21,000) (57).

In addition, the State of Florida Agency for Health Care Administration completed the questionnaire in Phase I. This information was added at the end due to the important MNT reimbursement information given by Florida's Medicaid department. 


\section{Survey Question 1:}

\section{Your insurance company offers which plan(s):}

The plans that these carriers provide are listed in Table 1. All the companies that responded offered an HMO plan 9 of the $9(100 \%)$. Seven of $9(78 \%)$ provided PPO plans. Only 3 of the $9(33 \%)$ offered the traditional third party payer plan. Six of the 9 $(67 \%)$ offered the federal insurance plan Medicare. Only 2 of $9(22 \%)$ had Medicaid accessible to their customers. This created a total of 27 plans among these 9 carriers.

\section{Survey Question 2:}

\section{Can you make decisions regarding claims for Medical Nutrition Therapy (MNT)?}

The survey population was primary insurance companies' top management for the 27 plans. Important health policies decisions are made at this level. Table 2 shows that Florida's carriers have the decision capabilities for MNT reimbursement. It was shown that a high percentage $(77 \%)$ or 21 of plans provide for decisions regarding MNT reimbursement. The 2 of 27 (7\%) carriers that offered Medicaid with their plans responded "Yes" that they make decisions about MNT reimbursement. Those carriers that offer HMO plans revealed 8 of the $27(30 \%)$ "Yes" answers. Medicare followed with 5 of 27 (18\%) stating "Yes" responses. Five of the 27 (18\%)"Yes" replies came from the PPO plans. The only plan that had a higher "No" answer was the indemnity plans. They had a negative response of 2 of the $27(7 \%)$ "No" answer rate. Table 2 shows that Florida's carriers have the decision capabilities for MNT reimbursement. 


\section{Survey Question 3:}

\section{What is your professional title?}

The professional titles of the participants completing the questionnaire are summarized in Table 3. The title of Medical Director was found to be the most common title with 6 of 9(67\%). Chief Medical Officer, Associate Director, and Registered Nurse each represented 1 of $9(11 \%)$ of the population.

\section{Survey Question 4:}

\section{Does your company have Registered Dietitians (RDs) providing medical nutrition?}

Table 4 highlights the trend that many 13 of $27(48 \%)$ health maintenance organizations are providing registered dietitian services. Carriers that provide Medicaid packages reveal 2 of $27(7 \%)$ "Yes" response rate, followed by HMO plans with 5 of 27 (19\%) providing for the services of Registered Dietitians. Three of 27 (11\%) of the carriers with Medicare plans and PPO plans responded "Yes". The indemnity plans did not offer registered dietitians services. The low rate of indemnity plans including registered dietitians may be attributed to their use of a more traditional health care services model.

\section{Survey Question 5:}

Does your company have a written policy on reimbursement for MNT?

The health care environment has emphasized cost containment and disease management, but are insurance companies writing policies to cover MNT? Florida carriers were asked if their company had any written policies on reimbursement for MNT. The majority of all companies responded "No" to this question as shown in Table 
5. All the indemnity plans revealed 3 of $27(11 \%)$ “No" marks for MNT policies. The PPO plans had 5 of $27(19 \%)$ "No" answers. Six of the HMO plans and 4 of the Medicare revealed "No" responses.

\section{Survey Question 6:}

\section{If yes, Please attach a copy.}

Although 7 companies stated they had a MNT reimbursement policy, only one company submitted a formal policy for MNT (Table 6). This MNT policy was for outpatient and inpatient parenteral and enteral nutrition therapy. This may have been created in response to the federal government benefit for such coverage in Medicare A and $\mathrm{B}$.

Another insurance company wrote their policy on the survey, which stated "Nutrition therapy is considered to be environmental or clinical ecology therapy and is a non-covered service. And Nutritional guidance is considered to be part of other services rendered (i.e.-nursing visit in a home health setting; physician visit; diabetic education)."

\section{Survey Question 7:}

\section{Do you reimburse for outpatient MNT case by case?}

Are Florida's carriers reimbursing for outpatient MNT on a case-by-case basis due to the lack of MNT policies? Registered Dietitians need to know is if their efforts in sending a reimbursement claim form are productive. For this question the results are tabulated on Table 7. Overall 21 of $27(77 \%)$ of these Florida insurance companies are reimbursing on a case-by-case basis. Two of $27(7 \%)$ of the Medicaid plans stated reimbursing individual cases. It was found that 8 of $27(30 \%)$ of the HMO plans are reimbursing on a case-by-case basis. Five of the 27 (19\%) of the PPOs and Medicare 
plans do respond to reimbursing case-by-case. The traditional plan had only 1 positive response.

\section{Survey Question 8:}

\section{If no, what department or person handles claims, pre-authorization?}

Question 8 dealt with the department that handles claims and pre-authorizations for the insurance companies. Registered Dietitians must know which department to contact regarding MNT reimbursement for their patients. This information, shown in Table 8 , is critical when attempting to obtain MNT reimbursement on a case-by-case basis. Only 4 of 9 (44\%) insurance companies completed this question. The documented departments were Health Services, Primary Care Physicians-orders, Claims Department, and Utilization Management; a fifth company stated it varies by location and contract. Results of this question show that each insurance company varies in its policy of who handles such claims.

\section{Survey Question 9:}

\section{Who reviews the case?}

Registered Dietitians need a contact title or name for communication purposes of medical necessity in MNT reimbursement for individual cases. Again, only 3 of $9(33 \%)$ individuals completed these questions. The answers provided for question 9 (Table 9) were "Medical Director" by two and an "IV Vendor" by one company. 


\section{Survey Question 10:}

\section{Is your criterion for reimbursement disease-state specific?}

MNT reimbursement is primarily done case-by-case. Proper coding techniques help ensure MNT reimbursement. Carriers were asked if they have a disease-specific criteria for MNT coverage (Table 10). The overall response from the plans was negative with 13 of 27 (48\%) "No" responses. The HMO plan had 4 of $27(15 \%)$ "Yes" and "No" rate. Similarly, the PPO plan had a 3 of $27(11 \%)$ “No" rate. The other plans had a higher negative response with Medicare plan had 4 of $27(15 \%)$ "No" answers. The two Medicaid plans both responded "No", while 2 of 27 (67\%) of the indemnity plans said "No".

\section{Survey Question 11:}

\section{If yes, which disease-state?}

The participants were asked to answer the above question with the disease state's IC9 code and corresponding maximum benefit allowance. The ranking of the diseasestates was based on an overview of all the plans due to the low response of individual plans. The top diseases by rank were: Diabetes (7), Morbid Obesity (6), Cardiac Disease (5), Inborn Error of Metabolism (5), High Risk Pregnancy, and Failure to Thrive (1) (Table 11). Only two completed the maximum benefit allowance question. One stated that they reimburse $70-80 \%$ Medicare allowable for all the listed diseases. The other carrier responded that Diabetes and Morbid Obesity have unlimited coverage for their HMO and PPO plans. It is possible that the lack of time or information or interest in maintaining privacy for this question limited responses to the question. 


\section{Survey Question 12:}

\section{What CPT codes does your company accept for MNT?}

At the implementation of this study there were no CPTs specifically for a Registered Dietitian to use. Now there are three new CPT codes for RDs to use on the claim form. The carriers were asked what CPT codes their company accepted for MNT. There was a low response rate by individual plan (Table 12). The most frequent were taken from an overview of all the plans. The CPT codes are listed first then followed by the ranking: 99204 Comprehensive (7), 99202 Expanded (6), 99212 Problem solving (6), 99203 Detailed (5), 99071 Education Supplies (5), 99214 Limited (5), 99213 Expanded (5), 99371 Telephone Conference (4), 99215 Complex (4), 99212 Problem solving (3), 99211 Minimal (3), 99080 Outcome Letter (2).

\section{Survey Question 12a:}

\section{Is a corresponding description necessary with the CPT?}

Registered Dietitians are concerned with describing their services so payment will be rendered. Much of the research suggests that a descriptor can influence whether a MNT reimbursement claim form is rejected or accepted. That is why question $12 \mathrm{a}$ was asked of these Florida insurance companies. Results were equivocal with 3 of 27 (11\%) stating "Yes" and 3 of $27(11 \%)$ carriers responding "No". The second part of the question dealt with the carriers documenting the actual descriptor. An overview of all the plans was used to derive the answers due to the low response for individual plans (Table 12a). The top corresponding descriptors in rank order were Medical Nutrition Therapy

(7), Disease Management Skills and Training (5), Nutrition Counseling (4), and Nutrition Assessment (3). 


\section{Survey Question 13:}

Would a medical necessity letter help in the case-by-case decision to reimburse for MNT?

The medical necessity letter is one factor that may increase MNT reimbursement. Florida's insurance companies responses are shown in Table 15. Seven of 27 (26\%) of the HMO plans responded "Yes". Also, 2 of 27 (7\%) of the indemnity plans, 4 of 27 (15\%) of Medicare and 4 of 27 (15\%) of PPO's were in favor of the medical necessity. The Medicaid plans had a "Yes" and a "No".

\section{Survey Question 13a:}

Would you accept a medical necessity letter with a Physician's diagnosis (ICD-9) and a Registered Dietitian's signature?

An outpatient $\mathrm{RD}$ needs to know if insurance companies will accept a medical necessity letter with a Physician's diagnosis (ICD-9) and a Registered Dietitian's signature for MNT reimbursement. Nine of $27(33 \%)$ did not respond to the question. However for the Florida carriers who did respond showed a trend toward allowing a RDs signature with an ICD-9 code to document medical necessity was seen (Table 13a). The HMO plan had 5 of 27 (19\%) that stated "Yes". Both Medicaid 1 of 27 (4\%) and Medicare 3 of 27 (11\%) plans had half their participants choose "Yes". The ideminity plan was split with 1 of 27 (4\%) replying "Yes" and 1 of 27 (4\%) relying "No".

\section{Survey Question 13(b):}

\section{Registered Dietitian's signature with Licensure or MS or PhD help?}

Can education and or state licensing influence an insurance company to increase the rate of MNT reimbursement? Do carriers notice professional titles when accepting or 
rejecting a superbill with a medical necessity letter? ADA and state dietetic associations spend a great amount of effort making sure our profession meets the highest education standards and state regulation requirements. Again there was a high 8 of $27(30 \%)$ "No Response" rate. Other plans, however, were in favor 11 of 27 (41\%) of documenting education merits and state regulations compared to 7 of $27(26 \%)$ who stated "No" to this question. The HMO plan showed the highest "Yes" rate with 5 of $27(19 \%)$ replies. The PPO plans follow with 3 of 27 (11\%) "Yes" responses. The Medicaid plans did document a "Yes" where the other was a "No" response. The two plans, Medicare and indemnity, were equal on their "Yes" and "No" answers.

\section{Survey Question 14:}

Do you use outcome documentation such as cost benefit analysis (CBA), with case studies or practice guidelines, in the decision to reimburse (policy, case-by-case) for MNT?

The current health care arena is concerned with cost effective medical care. But, are insurance companies using MNT outcome research and practice guidelines in their decision to create MNT policies? The "No" rate dominated the results for question 14 (Table 14). The HMO plans 5 of $27(19 \%)$ and Medicare plans 4 of $27(15 \%)$ had the highest "No" response. The majority of responses for the indemnity plans 2 of $27(7 \%)$ were also in the "No Response" section. The PPO plans had 3 of 27 (11\%) against using MNT information and outcome documentation. Overall, only 6 of $27(22 \%)$ answered this question in the affirmation. 


\section{Survey Question 15:}

(If no), Would you be interested in using CBA, case studies and/or practice guidelines, that show how nutrition services benefit your members and decrease costs to your company in your policy decision making for MNT reimbursement?

It is possible that the cause for the lack of MNT policies is the lack of knowledge on MNT by insurance companies. The Florida Dietetic Association and Registered Dietitians need to know if Medical Directors are interested in MNT outcomes and guidelines to create MNT reimbursement policies. Overall, 14 of $27(52 \%)$ indicated an interest in MNT outcome documentation in question 15 with only 4 of $27(15 \%)$ responding "No"(Table 15). The Medicare Plans produced 4 of 27 (15\%) wanting MNT outcome documentation. The HMO plans showed 5 of 27 (19\%) in favor with using MNT information for policy making. The PPO and indemnity plans had a positive "Yes" rate, where the Medicaid plans were split 50/50 between this question.

\section{Florida's Medicaid Questionnaire Response}

An overview of Florida's Agency for Health Care Administration Questionnaire for Phase I is shown on Table 16. This was the only completed questionnaire from phase I and contains valuable information for Florida's Registered Dietitians. The response to this questionnaire for its results showed that MNT services are supported through Medicaid. The Program Administrator completed the questionnaire. They have clear and concise MNT policies, which utilize many dietitians' services. MNT services are being reimbursed though the Developmental Services and Aged and Disabled Adults waiver. It was stated that a case manager reviews cases and the CPT codes were W9562 (Developmental Services) and W9721 (Aged/Disabled Adult). The Program 
Administrator stated "Yes" that they would be interested in using MNT outcome documentation and guidelines for developing MNT policy. 
Table 1. Plans offered by the surveyed insurance companies.

\begin{tabular}{ccccccc}
\hline Carrier & HMO & PPO & Indemnity & Medicare & Medicaid & Total \\
\hline 1 & $\mathrm{X}$ & $\mathrm{X}$ & & $\mathrm{X}$ & & 3 \\
2 & $\mathrm{X}$ & $\mathrm{X}$ & & $\mathrm{X}$ & & 3 \\
3 & $\mathrm{X}$ & $\mathrm{X}$ & $\mathrm{X}$ & $\mathrm{X}$ & & 4 \\
4 & $\mathrm{X}$ & & & & & 1 \\
5 & $\mathrm{X}$ & $\mathrm{X}$ & & $\mathrm{X}$ & $\mathrm{X}$ & 4 \\
6 & $\mathrm{X}$ & $\mathrm{X}$ & $\mathrm{X}$ & & & 3 \\
7 & $\mathrm{X}$ & $\mathrm{X}$ & & $\mathrm{X}$ & $\mathrm{X}$ & 4 \\
8 & $\mathrm{X}$ & $\mathrm{X}$ & $\mathrm{X}$ & $\mathrm{X}$ & & 4 \\
9 & $\mathrm{X}$ & & & & & 1 \\
\hline & 9 & 7 & 3 & 6 & 2 & 27 \\
\hline
\end{tabular}

Table 2. Participant's ability to make decisions for MNT reimbursement.

\begin{tabular}{lcccccc}
\hline Plan & Freq. Yes & $\%$ Yes & Freq. No & $\%$ No & No Resp. & Total \\
\hline HMO & 8 & 30 & 1 & 4 & 0 & 9 \\
PPO & 5 & 18 & 2 & 7 & 0 & 7 \\
Indemnity & 1 & 4 & 2 & 7 & 0 & 3 \\
Medicare & 5 & 18 & 1 & 4 & 0 & 6 \\
Medicaid & 2 & 7 & 0 & 0 & 0 & 2 \\
\hline Total & 21 & 78 & 6 & 22 & 0 & 27 \\
\hline
\end{tabular}


Table 3. The professional titles of the participants.

\begin{tabular}{lcc}
\hline Titles & Frequency & $\%$ \\
\hline Medical Directors & 6 & 67 \\
Chief Medical Officers & 1 & 11 \\
Associate Directors & 1 & 11 \\
Registered Nurse & 1 & 11 \\
\hline Total & 9 & 100 \\
\hline
\end{tabular}

Table 4. Carriers providing Registered Dietitians.

\begin{tabular}{lccccccc}
\hline Plans & Frequency & \%Yes & Frequency & \%No & No Resp. & \%N.R. & Total \\
\hline HMO & 5 & 19 & 4 & 15 & 0 & 0 & 9 \\
PPO & 3 & 11 & 2 & 7 & 2 & 7 & 7 \\
Indemnity & 0 & 0 & 1 & 4 & 2 & 7 & 3 \\
Medicare & 3 & 11 & 2 & 7 & 1 & 4 & 6 \\
Medicaid & 2 & 7 & 0 & 0 & 0 & 0 & 2 \\
\hline Total & 13 & 48 & 9 & 33 & 5 & 19 & 27 \\
\hline
\end{tabular}


Table 5. Do Florida's carriers have a MNT reimbursement policy?

\begin{tabular}{lccccccc}
\hline Plans & Freq. & $\%$ Yes & Freq. & $\%$ No & No Resp. & $\%$ N.R. & Total \\
\hline HMO & 3 & 11 & 6 & 22 & 0 & 0 & 9 \\
PPO & 1 & 4 & 5 & 19 & 1 & 14 & 7 \\
IND & 0 & 0 & 3 & 11 & 0 & 0 & 3 \\
Medicare & 2 & 7 & 4 & 15 & 0 & 0 & 6 \\
Medicaid & 1 & 4 & 1 & 4 & 0 & 0 & 2 \\
\hline Total & 7 & 26 & 19 & 70 & 1 & 4 & 27 \\
\hline
\end{tabular}

\section{Table 6. MNT Policies.}

\begin{tabular}{cl}
\hline Carriers & Policies \\
\hline 1 & n/a \\
2 & n/a \\
3 & Nutrition Therapy is considered to be environmental or clinical ecology therapy \\
& and is a non covered service. Nutrtional guideance is considered to be part of \\
& other services rendered (i.e. nursing visit in a home health setting physician \\
& visit, diabetic education). \\
4 & n/a \\
5 & n/a \\
7 & Out patient and inpatient coverage of parenteral and enteral nutrition therapy \\
8 & n/a \\
9 & n/a \\
\hline
\end{tabular}


Table 7. Are Florida's carriers reimbursing for outpatient MNT case-by-case?

\begin{tabular}{lccccccc}
\hline Plans & Freq. & $\%$ Yes & Freq. & $\%$ No & No Resp. & $\%$ N.R. & Total \\
\hline HMO & 8 & 30 & 1 & 4 & 0 & 0 & 9 \\
PPO & 5 & 19 & 1 & 4 & 1 & 4 & 7 \\
Indemnity & 1 & 3 & 1 & 4 & 1 & 4 & 3 \\
Medicare & 5 & 19 & 1 & 4 & 0 & 0 & 6 \\
Medicaid & 2 & 7 & 0 & 0 & 0 & 0 & 2 \\
\hline Total & 21 & 77 & 4 & 15 & 2 & 7 & 27 \\
\hline
\end{tabular}

Table 8. Department for claims or preauthorization.

\begin{tabular}{cl}
\hline Carriers & Departments \\
\hline 1 & No Response \\
2 & No Response \\
3 & Varies on locations and contract \\
4 & Claims Dept.and Utilization Management \\
5 & Primary Care Physicians \\
6 & No Response \\
7 & No Response \\
8 & No Response \\
9 & Health Services \\
\hline
\end{tabular}


Table 9. Who are the case reviewers?

\begin{tabular}{cl}
\hline Carriers & Title \\
\hline 1 & No Response \\
2 & No Response \\
3 & No Response \\
4 & Medical Director \\
5 & No Response \\
6 & No Response \\
7 & No Response \\
8 & IV-Vendor \\
9 & Medical Director \\
\hline
\end{tabular}

Table 10. Do carriers reimburse for specific diseases over other diseases for MNT?

\begin{tabular}{lccccccc}
\hline Plans & Freq. & \%Yes & Freq. & \%No & No Resp. \%No Resp. & Total \\
\hline HMO & 4 & 15 & 4 & 15 & 1 & 4 & 9 \\
PPO & 2 & 7 & 3 & 11 & 2 & 7 & 7 \\
Indemnity & 1 & 4 & 0 & 0 & 2 & 7 & 3 \\
Medicare & 1 & 4 & 4 & 15 & 1 & 4 & 6 \\
Medicaid & 0 & 0 & 2 & 7 & 0 & 0 & 2 \\
\hline Total & 8 & 30 & 13 & 48 & 6 & 22 & 27 \\
\hline
\end{tabular}


Table 11. Ranking of disease States that are more often reimbursed for MNT.

\begin{tabular}{clcc}
\hline Question & Disease & Frequency & Rank \\
\hline c & Diabetes & 7 & 1 \\
f & Morbid Obesity & 6 & 2 \\
b & Cardiac Diseases & 5 & 3 \\
j & Inborn Error of Metabolism & 5 & 3 \\
h & High Risk Pregnancy & 2 & 4 \\
g & Failure to Thrive & 1 & 5 \\
\hline
\end{tabular}


Table 12. CPT codes accepted for MNT.

\begin{tabular}{clcc}
\hline Question & CPT Codes & Frequency & Rank \\
\hline a & 99204-Comprehensive & 7 & 1 \\
b & $99203-$ Detailed & 5 & 3 \\
c & $99202-$ Expanded & 6 & 2 \\
d & 99201 -Problem Solving & 6 & 2 \\
e & $99371-$ Telephone Conference & 4 & 4 \\
f & 99071 -Education Supplies & 5 & 3 \\
g & $99215-$ Complex & 4 & 4 \\
h & $99214-$ Limited & 5 & 3 \\
I & $99213-$ Expanded & 5 & 3 \\
j & $99212-$ Problem Solving & 3 & 5 \\
k & $99211-$ Minimal & 3 & 5 \\
I & $99080-$ Outcome letter & 2 & 6 \\
\hline
\end{tabular}

Table 12a. CPT descriptors frequently accepted for MNT.

\begin{tabular}{clcc}
\hline Question & CPT Descriptors & Frequency & Rank \\
\hline c & Medical Nutrition Therapy & 6 & 1 \\
d & Disease-Management & 4 & 2 \\
e & Nutrition Assessment & 3 & 4 \\
f & Nutrition Counseling & 3 & 3 \\
g & Other & 1 & 5 \\
\hline
\end{tabular}


Table 13. Does a medical necessity letter influence the rate of reimbursement?

\begin{tabular}{lccccccc}
\hline Plans & Freq. & $\%$ Yes & Freq. & $\%$ No & No Resp. & $\%$ N.R. & Total \\
\hline HMO & 7 & 26 & 2 & 7 & 0 & 0 & 9 \\
PPO & 4 & 15 & 3 & 11 & 0 & 0 & 7 \\
Indemnity & 2 & 7 & 1 & 4 & 0 & 0 & 3 \\
Medicare & 4 & 15 & 2 & 7 & 0 & 0 & 6 \\
Medicaid & 1 & 4 & 1 & 4 & 0 & 0 & 2 \\
\hline Total & 18 & 67 & 9 & 33 & 0 & 0 & 27 \\
\hline
\end{tabular}

Table 13a. The acceptance rate of a medical necessity letter with an ICD-9 code and Registered Dietitian signature.

\begin{tabular}{lccccccc}
\hline Plans & Freq. & $\%$ Yes & Freq. & $\%$ No & No Resp. & $\%$ N.R. & Total \\
\hline HMO & 5 & 19 & 2 & 7 & 2 & 7 & 9 \\
PPO & 3 & 11 & 1 & 4 & 3 & 11 & 7 \\
Indemnity & 1 & 4 & 1 & 4 & 1 & 4 & 3 \\
Medicare & 3 & 11 & 1 & 4 & 2 & 7 & 6 \\
Medicaid & 1 & 4 & 0 & 0 & 1 & 4 & 2 \\
\hline Total & 13 & 48 & 5 & 19 & 9 & 33 & 27 \\
\hline
\end{tabular}

Table 13b. The influence of licensure, MS, or PhD on the acceptance of MNT reimbursement.

\begin{tabular}{lccccccc}
\hline Plans & Freq. & \%Yes & Freq. & \%No & No Resp. & \%N/ R & Total \\
\hline HMO & 4 & 15 & 3 & 11 & 2 & 7 & 9 \\
PPO & 3 & 11 & 1 & 4 & 3 & 11 & 7 \\
IND & 1 & 4 & 1 & 4 & 0 & 0 & 2 \\
Medicare & 2 & 7 & 2 & 7 & 2 & 7 & 6 \\
Medicaid & 1 & 4 & 0 & 0 & 1 & 4 & 2 \\
\hline Total & 11 & 41 & 7 & 26 & 8 & 30 & 26 \\
\hline
\end{tabular}


Table 14. Carrier's use of MNT outcome documentation.

\begin{tabular}{lccccccc}
\hline Plans & Freq. & $\%$ Yes & Freq. & $\%$ No & No Resp. & $\%$ N.R. & Total \\
\hline HMO & 3 & 11 & 5 & 19 & 1 & 4 & 9 \\
PPO & 1 & 4 & 3 & 11 & 3 & 11 & 7 \\
Indemnity & 1 & 4 & 0 & 0 & 2 & 7 & 3 \\
Medicare & 0 & 0 & 4 & 15 & 2 & 7 & 6 \\
Medicaid & 1 & 4 & 1 & 4 & 0 & 0 & 2 \\
\hline Total & 6 & 22 & 13 & 48 & 8 & 30 & 27 \\
\hline
\end{tabular}

Table 15. Carrier's interest in MNT outcome documentation.

\begin{tabular}{lccccccc}
\hline Plans & Freq. & $\%$ \%es & Freq. & $\%$ No & No Resp. & $\%$ N.R. & Total \\
\hline HMO & 5 & 19 & 1 & 4 & 3 & 11 & 9 \\
PPO & 3 & 11 & 1 & 4 & 3 & 11 & 7 \\
Indemnity & 1 & 4 & 0 & 0 & 2 & 7 & 3 \\
Medicare & 4 & 15 & 1 & 4 & 1 & 4 & 6 \\
Medicaid & 1 & 4 & 1 & 4 & 0 & 0 & 2 \\
\hline Total & 14 & 52 & 4 & 15 & 9 & 33 & 27 \\
\hline
\end{tabular}


1) Your insurance company is a (an): Medicaid Home \& Community Based Services Waiver.

2) Can you make decisions regarding claims for Medical Nutrition Therapy (MNT)? No

3) What is your professional title: Program Administrator

4) Does your company have a written policy on reimbursement for MNT? Yes, The Developmental Services wavier has Dietitian services and Aged and Disabled Adults waiver and has Nutritional Risk Reduction and Home Delivered Meals. The policy is as follows "Dietitian services are conducted by a licensed dietitian or nutritionist, the service provided include assessing nutritional needs and status using appropriate data; recommending appropriate dietary regiment, nutritional support and nutrient intake; improving health status, counseling, and education; and developing, implementing, and managing nutrition care systems, which include evaluation, modifying, and maintaining appropriate standards of high quality in food and nutrition care services. The Nutrition Risk Reduction services include assessment and guidance provided for the recipient and/or caregiver in the planning and preparation of nutritionally appropriate meals.

5) Do you reimburse for outpatient MNT case by case? Yes

6) N/A.

7) Who reviews the cases? Title: Case Manager

8) Is your criterion for reimbursement disease-State specific? No

9) N/A

10) What CPT codes does your company accept for MNT?

W9562 (Developmental Services)

W9721 (Aged/Disabled Adult)

11) Is a corresponding description necessary? No

12) Would a medical necessity letter help in the case-by-case decision to reimburse for MNT? No

12a) N/A

13) Do you use outcome documentation? No

14) Would you be interested in using outcome documentation? Yes 


\section{CHAPTER V}

\section{DISCUSSION}

The targeted distribution of the revised questionnaire allowed for an adequate response rate. The participants were mainly top administrators and extremely hard to contact. The study was accomplished through the persistence of the researcher, and by contacting their assistants and using express delivery for the questionnaire. This shows that the dietetic profession can make an impact on this population with persistent marketing. The questionnaire was developed to tackle the most critical MNT reimbursement issues, as well as bring an awareness of MNT issues to top health insurance administrators. The results of the questionnaire used for this section were from all the surveyed carrier's HMO plans. The other plans (PPO, Medicare, Medicaid and Indemnity) were two small to generalize, but are shown in overall trends for the 27 plans representing all the carriers.

The majority of the respondents were Medical Officers and Medical Directors. Others respondents included an Associate Director and a Registered Nurse. It is encouraging for registered dietitians that medical directors were willing to complete surveys that deal with MNT reimbursement. Persons in these top to middle management positions enhance and create future MNT policies.

Using a regional survey of third party MNT reimbursement policies, a similar study by Ohio's NSPS assessed middle to top insurance management positions capable of making or changing insurance MNT policies (54). They found that $44 \%$ of those who responded worked on the vice-president or manager level of the claims/benefit division. And, 59\% had final authority or access in the decision making process for MNT policies. 
This study showed that 6 of 27 (67\%) Medical Directors were the predominant title for the respondents. The overall trend of the respondent's offered insurance plans indicated a high level 21 of 27 (78\%) of decision-making capacity for MNT claims in the State of Florida. These policy makers influence what type of coverage the $\mathrm{RD}$ will receive in the health field.

RD's services are available throughout Florida's surveyed carriers. Almost half of all the plans represented in the present study provided RD services. Similar findings were found in Hassell et al Ohio regional survey with the added response that an $\mathrm{RD}$ needed a physician's referral (43).

The Connecticut NSPS Committee conducted an audit of dietitians actual reimbursement rate (49). One of the major reasons that reimbursement was denied for the Connecticut study was that RDs were considered not a covered provider. In 2000, Medicare approved RDs as covered providers for patients with diabetes and renal disease $(13,56)$. This is an important accomplishment by ADA to obtain federal acknowledgment for our professional services. This may influence private health care companies to establish RDs as covered providers.

Florida sets a poor example of insurance companies providing any written policy specific to MNT. A profile of reimbursement for Utah's study documented a $45 \%$ positive rate for nutrition policies, along with finding that HMOs were providing more MNT reimbursement policies (50). The two companies in this study sent or wrote their policies were HMOs. One company sent back a policy for IV nutrition services; and another wrote two policies for MNT on the survey. These two policies explained why MNT would have a poor reimbursement rate. Their definition of nutrition service did not 
equate to our professional services. The most appropriate MNT policy was from Florida's Health Care Administration Medicaid waiver in Phase I (Table 16). It encompassed a majority of our profession's services.

Since past studies stated that MNT policies were lacking in the insurance field, the question of reimbursement for MNT case-by-case was asked to the participants. The majority of participants do reimburse for MNT on individual cases. It is evident from this study that RDs can summit claims for MNT on an individual basis even without MNT policies. The claim form can even be a marketing tool to educate insurance management.

There are many factors that these insurance companies look at when reimbursing on individual cases. Communication of these factors to the appropriate department and personnel would establish a higher chance of coverage. Our results, though small, showed a variety of different departments titles and persons responsible for claims or preauthorizations. A recommendation from these results is for Florida's RDs to begin to target medical directors. In this manner they may educate and continue to make strides for MNT reimbursement both personally and professionally.

It is essential that communication links and relationships be formed between the $\mathrm{RD}$ and personnel responsible for approval of financial coverage. Liskov et al stated that one of the first steps in achieving coverage is to establish a relationship with the insurance company (13). This way the RD will have the insurance companies' MNT policies, contact names and departments when needed for patient coverage. The ADA has recently produced a marketing kit to help RDs present the profession to local thirdparty payers, employer insurance, and hospital finance and billing departments. As RDs 
work to establish relationships with CMOs in insurance companies they can use materials in this kit to educate them about the benefits of MNT coverage (58).

The potential MNT reimbursable diseases found in this study were similar to those of several studies $(42,43,46-48,54)$. HMOs were more likely 4 of $27(15 \%)$ to reimburse for specific diseases than any other plan. However, the overall percentage for all the plans in the present study was slightly lower than that reported in other research literature $(43,49)$.

The response was low when participants were asked what specific disease states were covered and to give the corresponding maximum benefit allowance. Diabetes, morbid obesity, and cardiac disease were the three top ranking disease States. Past research had diabetes and cardiac disease as the top nutrition service related diseases for MNT reimbursement $(23,43,49,54)$. Only two carriers responded regarding the maximum benefit allowance: one reimbursed for $70-80 \%$ of Medicare allowable for all the listed diseases and the second carrier had unlimited coverage for their HMO and PPO for diabetes and morbid obesity. Even though the response was small for the specific coverage, similar findings occurred with a survey by Hassell (43).

The top CPT codes and descriptors found in this study are a combination of all the carriers' plans, due to the low response. No other survey has asked about CPT codes. However, results of the Ohio Statewide survey of insurance companies' regarding MNT reimbursement practices showed that $84 \%$ did not know or would not reveal the usual and customary reimbursement (UCR) practice of their company (54). This suggests that carriers don't reveal their actual reimbursement practices. 
Schatz (52) revealed potentially applicable CPT codes for nutrition services in 1993. Results of this study show the top four CPT codes, (7) 99204, (6) 99202, (6) 99201, (5) 99203, were found on Schatz's list. This suggests that carriers do recognize these CPT codes for nutrition services. RDs, even without specific CPT codes, should use these CPT codes. From Phase II Florida's Medicaid home and community-based services waivers documented two HCPCS, (W9562-Developmental Services) and (W9721 Aged/Disabled Adults), for MNT coverage.

There are three new CPT codes $(97802,97803,97804)$ that the American Medical Association and Health Care Financing Administration (HCFA) or now called the Center for Medicare and Medicaid Services (CMS) recognized for Medicare reimbursement. The new codes will cover diabetic and non-dialysis Medicare patients for MNT care $(13,14)$. These codes were established after the implementation of this study.

Inclusion of corresponding descriptors for the CPT codes was considered necessary for half of the carriers that responded to that question. Reimbursement may not occur without the appropriate terminology (49). Medical nutrition therapy was most recognized as a descriptor of nutrition services. It appears from this result that insurance companies in the State of Florida are accepting nutrition terminology.

Another factor was the inclusion of a medical necessity letter. This study found (67\%) of the plans would approve MNT reimbursement with a medical necessity letter. A medical letter with a physician's diagnosis (ICD-9) and RD signature and state license, MS, or PhD would help obtain coverage. This shows that a medical necessity letter would have a positive effect on MNT reimbursement. Similarly, Bolonda et al (46) did a study at a nutrition clinic in Thousand Oaks, California where they concluded from their 
findings that documentation of medical necessity for individual cases increased MNT reimbursement.

It was found that a low percentage 6 of 27 (22\%) of CMOs are using cost benefit analyses (CBA) with case studies and practice guidelines for their decision for MNT policies in the State of Florida. This may be due to a lack of understanding by the top management of what MNT services, practice guidelines, and cost-effectiveness can provide their company and customers $(26,52)$. No other study assessed the usage of the CBA with the CMOs in the health care insurance industry.

Results of this survey indicate an encouraging 14 of 27 (52\%) of all plans in favor of using CBA with case studies or practice guidelines to produce MNT policies. Also, in Phase I The State of Florida Agency For Health Care Administration stated an interest in CBA, case studies, and practice guidelines. It is optimistic that CMOs and government agencies are willing to learn more about the benefits of the dietetic profession. Successful communication with the CMO can produce MNT policies on reimbursement. Many studies have shown that with communicating MNT cost-effectiveness, MNT reimbursement has been achieved $(23,42,37)$. The importance of the dietetic profession involvement in assisting top management in making MNT policies cannot be overstated $(36,42,43,46-48,54)$.

In this competitive health care arena RDs are making important advances in insurance coverage for MNT. The dietetic profession is making advances by taking a positive approach in marketing our services both federally and privately in the health care industry. The new Medicare provision will influence new policies for the private health industry. It is evident from the results of this study that many of the insurance companies 
in Florida are reimbursing for MNT services. It is critical to stay knowledgeable about who, what, and why the insurance industry is reimbursing for these services. This study created a questionnaire that analyzed these questions for Florida's insurance industry and provided some valuable answers. 


\section{CHAPTER VI}

\section{CONCLUSION}

The years of little reimbursement are in the past for RDs working in outpatient or private practice. There is an optimistic outlook for RDs being a valued provider for health care services. The new status of RDs under Medicare provisions for diabetic and renal patients creates hope for the growth of our profession and more nutrition services for the public. ADA has worked hard to achieve the passage of the Medicare MNT Act of 2001 which shows they are striving to achieve nutrition related diseases to be treated under the RD's care (56).

The new Medicare Wellness Act of 2001 emphasizes the maintenance and preventive care of the elderly (56). The top recommendations are for MNT for elderly patients with cardiovascular diseases to be covered. A group of bipartisan lawmakers created the Act based on the recommendation of the U.S. Preventive Services Task Force and the Institute of Medicine. Lawmakers are starting to understand that the dietetic profession can positively impact patient outcomes. ADA continues to make political accomplishments at the federal and state level, which will lead to an increase in MNT coverage. But, it will take time and patience for RDs to obtain full payment of all MNT services.

Even with these accomplishments the dietetic profession still needs to forge ground in the private sector as well. The results of the study provide the assistance needed to obtain the most MNT coverage in an outpatient setting. The following recommendations will inform RDs of Florida's insurance industry criteria for MNT coverage in the outpatient setting. 


\section{$\underline{\text { Recommendations }}$}

In order to increase the probably of reimbursement RDs should adhere to the following:

1. Establish a contact department and name of the person responsible for approval for claims for MNT coverage. Over time, the RD will create a professional relationship that can simplify problems for individual MNT coverage. The researcher highly recommends using ADA's Medical Nutrition Therapy Works marketing kit as a great communication tool when establishing a presence at an insurance company.

2. Results of this study show that Florida insurance companies primarily allow for MNT coverage on individual cases. Proper documentation and communication are required from the $\mathrm{RD}$ to assure acceptance case-by-case. The insurance companies are in their infancy state for establishing MNT policies. Federal MNT policies are just being formed. It will take time for private insurance companies to follow Medicare's provisions.

3. When submitting a HCFA 1500 or superbill for services rendered, note the following: Always send a medical necessity letter with anticipated practice guideline and outcome along with an ICD-9 and your professional signature plus any additional education $(\mathrm{MS}, \mathrm{PhD})$ or license credential(s). Although not included in the study, the new Medicare CPT codes should be accepted at the current time.

\section{Most Accepted CPT codes}

- 99204-Comprehensive 45minutes,

- 99203-Detailed 30minutes,

- 99202 Expanded 20 minutes,

- 99201-Problem Solving 10 minutes. 


\section{$\underline{\text { Top descriptors }}$}

- Medical Nutrition Therapy

- Disease Management.

\section{Florida's HCFA codes for Medicaid}

- W9562 Developmental Services and

- W9721 Aged/Disabled Adults.

4. The Florida Dietetic Association can conduct an annual report card or audit on Florida's insurance companies targeting Chief Medical Officers or administrators responsible for policy making. The insurance industry has a managed care report, the Health Plan Employer Data and information Set (HEDIS) (59). This report card documents each insurance company's health care performance. Nutrition measures are not on this performance review. We need to make our own report card for Registered Dietitians and consumers for the best insurance companies with MNT. This will keep our profession up on the latest MNT coverage in the health insurance industry.

5. The questionnaire form used in this survey would make a good tool for the annual audit. The researcher recommends using express delivery for direct contact of the survey to the CMO. The researcher found that this increases the rate of delivery to the high position executives, and thus an increased response rate.

6. A strong recommendation is for health insurance industry education at the university level for undergraduate (future Registered Dietitians) and graduate students (Registered Dietitians). Knowledge is the key to strengthening MNT's position in the health insurance arena. A RD that is knowledgeable about the insurance process will be more confident in assertively becoming active in the MNT reimbursement process. 
7. Encourage RDs to start their own reimbursement billing practices for either outpatient hospitals or private practice settings. For example, the Commission on Dietetic Registration's newly implemented Professional Development 2001, professional credentialing system, allows for continuing education credits for establishing a MNT billing process as a professional goal as part of the continuing credit requirements. Attending lectures, completing self-study kits, or work under a mentor for MNT reimbursement could also be included. 


\section{BIBLIOGRAPHY}

1. Byer P, et al. Reimbursement And Insurance Coverage for Nutrition Services. Chicago, IL: The American Dietetic Association; 1991.

2. Stollman L, et al. Nutrition Entrepreneur's Guide to Reimbursement Success. Chicago, IL: The American Dietetic Association; 1995.

3. Johnson RK, Coulston AM. Medicare: Reimbursement rules, impediments, and opportunities for dietitians. J Am Diet Assoc. 1995; 95:1378-1380.

4. Nutrition Services Payment System: Guidelines for Implementation. Chicago, Ill: The American Dietetic Association; 1985.

5. Neville JN, Gilmore CJ. President's Page: A report on Nutrition Services Payment System activities. J Am Diet Assoc. 1988; 88:953-955.

6. Coulston A, Gallagher A, Splett P, Story M, Mullis R. Health care reform legislative platform: Economic benefits of nutrition services. J Am Diet Assoc. 1993; 93:686-690.

7. Coulston AM. Health care reform: ADA's number one priority. Top Clin Nutr. 1990; 11:1-3.

8. Looking ahead at public policy and the $105^{\text {th }}$ Congress. J Am Diet Assoc. 1997; 97:17.

9. Legislative initiatives for health care reform: An analysis of five proposals, including the Clinton plan. J Am Diet Assoc. 1993; 93:1256-1258.

10. Health care reform gets back on track. J Am Diet Assoc. 1994; 94:840.

11. ADA promotes dietitian's role as a "certified provider' of diabetes self-management training under Medicare Part B. J Am Diet Assoc. 1998; 98:131-132.

12. ADA's Medical Nutrition Therapy Campaign reaches milestone. J Am Diet Assoc. 1997; 97:1092.

13. Liskov T. Putting Together The Pieces On Reimbursement. Dietitian's Edge. 2001; 2:44-48.

14. Myers EF, Michael P, Duester KC. Tips for contract negotiations and establishing MNT rates. J Am Diet Assoc. 2001; 101:624-626.

15. National Academy of Science, Institute Of Medicine, The Role of Nutrition in Maintaining Health in the Nation's Elderly: Evaluating Coverage of Nutrition Services for the Medicare Population, Nat'l Acad Press, Dec. 15, 1999. 
16. Michael P. The three Cs of MNT: coverage, codes, and compensation. J Am Diet Assoc. 2000; 100:1140-1141.

17. The Florida Dietetic Association. A Position Paper: Health Care Reform in Florida. 1993.

18. State and federal efforts to trim health care costs embrace Medicaid waivers and managed care. J Am Diet Assoc. 1995; 95:750.

19. Medicaid reform efforts shift to the States. J Am Diet Assoc. 1995; 95:1262.

20. State test health care reform through Medicaid waivers. J Am Diet Assoc. 1995; 95:302.

21. What's the outlook for health care reform? J Am Diet Assoc. 1995; 95:649.

22. North Dakota Dietetic Association. Practice Guidelines. 1995.

23. Anderson P, Webb AR. Negotiating nutrition reimbursement. Top Clin Nutr. 1996; $11: 33-42$.

24. Derelian D, Gallagher A, Snetselaar L. President's Page: Letting the outcome justify the reimbursement. J Am Diet Assoc. 1995; 95:371.

25. Eck L, Slawson DL, Williams R, Smith K, Clayton-Harmon K, Oliver D. A model for making outcomes research standard practice in clinical dietetics. J Am Diet Assoc. 1998; 98:451-457.

26. Gould RA. The next rung of the ladder: Achieving and expanding reimbursement for nutrition services. J Am Diet Assoc. 1991; 91: 1383-1384.

27. Inman-Felton A, Smith KG, Johnson EQ, eds. Medical Nutrition Therapy Across The Continuum Of Care: Supplement 1,2. Chicago, IL: The American Dietetic Association and Morrison Health Care, Inc; 1997.

28. ADA protocols help secure coverage of medical nutrition therapy by Blue Cross Blue Shield of Massachusetts. J Am Diet Assoc. 1998; 98:18.

29. Gallagher-Allred CR. Reimbursement Success: Coverage and Reimbursement for Nutrition Services. Columbus, OH: Ross Laboratories; 1993.

30. Business Success in Dietetics: Generating Revenue and Saving Costs. Columbus, OH: Ross Laboratories; 1990.

31. Splett PL. Effectiveness and cost effectiveness of nutrition care: A critical analysis with recommendations. J Am Diet Assoc. 1991; 91(suppl):S1-53. 
32. Disbrow DD. The costs and benefits of nutrition services: A literature review. J Am Diet Assoc. 1989; 89(suppl):S3-S-55.

33. Health care reform legislative platform: Economic benefits of nutrition services. $J$ Am Diet Assoc. 1993; 93:686-700.

34. Carey M, Gillespie S. Position of The American Dietetic Association: Costeffectiveness of medical nutrition therapy. J Am Diet Assoc. 1995; 95:88-91.

35. Egan MC, Kaufman M. Financing nutrition services in a competitive market. J Am Diet Assoc. 1985; 85:210-215.

36. Laramee SH. Position of the American Dietetic Association: Nutrition services in managed care. J Am Diet Assoc. 1996; 96:391-395.

37. Edelman RD, Johnson RK, Coulston AM. Securing the inclusion of medical nutrition therapy in managed care health systems. J Am Diet Assoc. 1995; 95:1100-1102.

38. Michalczyk D. Complementary/alternative medicine: Another path to MNT coverage? J Am Diet Assoc. 2000; 100:632-633.

39. Johnson EQ, Valera S. Medical Nutrition therapy in non-insulin-dependent diabetes mellitus improves clinical outcome. J Am Diet Assoc. 1995; 95:700-701.

40. Schiller MR, Miller A, Moore C, Davis E, Dunn A, Mulligan K, Zeller P. Patients report positive nutrition counseling outcomes. J Am Diet Assoc. 1998; 98:977-982.

41. Sikand G, Kashyap ML, Yang I. Medical nutrition therapy lowers serum cholesterol and saves medication costs in men with hypercholesterolemia. J Am Diet Assoc. 1998; 98:889-894.

42. Weese N, Jones J, Miller MA. Successful strategies for reimbursement of outpatient nutrition services. J Am Diet Assoc. 1993; 93:458-459.

43. Hassell J, Rood R, McDowell A. A regional survey of third-party reimbursement policies for nutrition services. J Am Diet Assoc. 1990; 90:710-712.

44. Baranoski CL, King SL. Insurance companies are reimbursing for medical nutrition therapy. J Am Diet Assoc. 2000; 100:1530-1532.

45. Fatzinger P. Reimbursement for outpatient nutrition services. Top Clin Nutr. 1996; 11:43-47.

46. Bolonda KL, Lacagnina S, Dahl L, Murphy M, Hunt IF. Strategies for increasing third-party reimbursement for nutrition counseling. J Am Diet Assoc. 1994; 94:390-392. 
47. Smith KG, Michels FG. Who's paying for nutrition services? Billing, coding and reimbursement tends. J Am Diet Assoc. 1993; 93:1255.

48. Smith AE, Smith PE. Reimbursement for clinical nutrition services: A 10-year experience. J Am Diet Assoc. 1992; 92:1385-1388.

49. Bell LS, Chavent G, Hessler N, Zehalla M. Conducting a third-party reimbursement survey: Experience of the Connecticut nutrition services payment systems committee. J Am Diet Assoc. 1990; 90:82-86.

50. Gould R, Ernst SL, Fairchild GT. Reimbursement for nutrition services: Profile of third-party payers in Utah. J Am Diet Assoc. 1989; 89:696-698.

51. Cross N. Assessing fees for nutrition counseling. J Am Diet Assoc. 1981; 79:57-59.

52. Schatz GB. Coding for nutrition services: Challenges, opportunities, and guidelines. J Am Diet Assoc. 1993; 93:471-477.

53. Finn SC, Gillespie S, Mathieu-Harris M. President's Page: Insurance coverage and reimbursement-communicating in 'code'. J Am Diet Assoc. 1993; 93:47.

54. Rood RS, Griffith M. The Ohio NSPS Statewide survey of third-party reimbursement policies for nutrition services. J Am Diet Assoc. 1993; 93:181-182.

55. Michalczyk D. MNT works: Marketing resources spread the message. J Am Diet Assoc. 2001; 101:740.

56. ADA. Washington Wire. Dietetics in Practice. 2001; 1.

57. Florida Trend:1998 Annual TopRank Florida. St.Petersburg, Fl .Trend Magazine, Inc. 1997; 70-74.

58. American Dietetic Association's Health Care Financing Team. Medical Nutrition Therapy Works Marketing Kit. Chicago, IL: The American Dietetic Association; 2001.

59. Turner MA, Dwyer T. Nutrition measures for managed care report cards. J Am Diet Assoc. 1996; 96:374-380. 
APPENDICES 


\section{APPENDIX A}

\section{Cover Letter}

Manuel Anton, M.D.

Healthchoice/ Community Health Care Systems Inc.

2301 Lucien Way

Suite 440

Maitland F1 32751

I am a graduate student at Florida International University in Miami, Florida finishing my thesis work for a Master of Science in Dietetics and Nutrition. Enclosed is a survey for my thesis regarding your policies on and reimbursement trends for outpatient Medical Nutrition Therapy. Directions for the survey are on top of page one. If you do not have the information needed please give the survey to the appropriate person. If you have any questions please call me at (954) 430-8985.

Your input will provide critical information needed for effective communication between Registered Dietitians and insurance companies. This will allow the necessary patients (ex. diabetic, heart disease) access to medical nutrition therapy. Again, thank you for you time. Completed surveys can be returned in the enclosed prepaid and addressed Federal Express envelope.

Thank You,

Katherine Cabrera 


\section{APPENDIX A (Continued)}

\section{Questionnaire}

\section{QUESTIONNAIRE}

There are five different plans listed below. Check and fill in the appropriate information for your company. If you have additional questions please call Katherine Cabrera at (954) $430-8985$

Company Name:

Date (MM/DD/YYYY):

1) Your insurance company offers which plan(s):
$\square$ (a) HMO
$\square$ (b) PPO
$\square$ (c) INDEMNITY (IND)
$\square(\mathrm{d}) \mathrm{MEDICARE}$ (CARE) $\square$ (e)MEDICAID (CAID)

2) Can you make decisions regarding claims for Medical Nutrition Therapy (MNT)?
HMO $\square$ (a) Y
PPO $\square$ (a) Y
IND $\square$ (a) $Y$
CARE $\square$ (a) Y
CAID $\square$ (a) Y
\begin{tabular}{|l}
\hline (b) $N$ \\
\hline (b) $N$ \\
$\square$ (b) $N$ \\
$\square$ (b) $N$ \\
$\square$ (b) $N$
\end{tabular}

3) What is your professional title:

(a)

4) Does your company have Registered Dietitians (RDs) providing medical nutrition therapy to your customers? HMO $\square$ (a) Y
PPO
IND
(a) $\mathrm{Y}$
CARE
(a) $Y$
CAID $\square$ (a) Y
(b) $\mathrm{N}$
(b) $\mathrm{N}$
(b) $\mathrm{N}$
(b) $\mathrm{N}$

(b) $\mathrm{N}$

5) Does your company have a written policy on reimbursement for MNT?
HMO
(a) $\mathrm{Y}$
PPO
(a) $\mathrm{Y}$
IND
(a) $\mathrm{Y}$
CARE
(a) $\mathrm{Y}$
CAID
(a) $\mathrm{Y}$
$\square$ (b) $\mathrm{N}$
(b) $\mathrm{N}$
(b) $\mathrm{N}$
(b) $\mathrm{N}$
(b) $\mathrm{N}$

6) If yes, Please attach a copy in the return Federal Express envelope. $\square$ (a) Y $\square$ (b) $N$

7) Do you reimburse for outpatient MNT case by case?

HMO $\square$ (a) Y

PPO $\square$ (a) Y

IND $\square$ (a) Y

CARE $\square$ (a) Y

CAID $\square$ (a) Y

$\square$ (b) $N$
(b) $N$
$\square$ (b) $N$
$\square$ (b) $N$
$\square$ (b) $N$


8) If no, what department or person handles claims?

(MCO)

What department handles pre-authorizations?

(or)

(INDEMNITY)

What department handles Claims?

(a)

(a)

9) Who reviews the cases. Title:

(a)

If 4, 5 and 6 are NO (company does not reimburse) then skip to question \# 13.

10) Is your criterion for reimbursement disease-state specific?

HMO $\square$ (a) Y
PPO $\square$ (a) Y
IND $\square$ (a) Y
CARE $\square$ (a) Y
CAID $\square$ (a) Y

\begin{tabular}{|l}
$\square$ (b) N \\
$\square$ (b) N \\
$\square$ (b) N \\
$\square$ (b) N \\
$\square$ (b) N
\end{tabular}

11) If yes, which disease-state

HMO

Aids

Cardiac Diseases (Htn,Hyperlipidemia,CAD)

Diabetes (Type I \& II Gestation)

Eating Disorders (Anorexia,Bulimia,Binge Eating,)

Morbid Obesity

Failure To Thrive (Peds)

High Risk Pregnancy

Renal Disease (Acute \& Chronic)

Inborn Error of Metabolism (PKU)
IC9 Code

(a)

(b)

(c)

(g)

(h)

(i)

(j)
Max. Benefit

Allowance

(k)

(l)

(m)

(n)

(o)

(p)

(q)

(r)

(s)

PPO

IC9 Code

\section{Aids}

Cardiac Diseases (Htn,Hyperlipidemia,CAD)

Diabetes (Type I \& II Gestation)

Eating Disorders (Anorexia,Bulimia,Binge Eating,)

Morbid Obesity

Failure To Thrive (Peds)

High Risk Pregnancy

Renal Disease (Acute \& Chronic)

Inborn Error of Metabolism (PKU) (a)

(b)

(c)

(h)

(i)

(j)
Max. Benefit

Allowance

(k)

(m)

(n)

(o)

(p)

(q)

(r)

(s) 
Aids

Cardiac Diseases (Htn,Hyperlipidemia,CAD)

$\underline{\text { IC9 Code }}$

(a)

(b)

(c)

(g)

(h)

(i)

(j)

\section{IC9 Code}

(a)

(b)

(c)

(j)

IC9 Code

(a)

(b)

(c)

(e)

(i)

(j)
Allowance

(k)

Max. Benefit

Allowance

(k)

(1)

(m)

(s)

Max. Benefit

Allowance

(k)

(m)

(n)

(o)

(p)

(q)

(r)

(s)

12) What CPT codes does your company accept for MNT?

Examples: Georgia Department of Medical Assistance, admin. Medicaid, two CPT for Licensed Dietitians: 99203 , 99213

North Dakota Blue Cross Blue Shield 99201, 99202,99211, 99212)

$\mathrm{HMO}$

New Patient

$\begin{array}{ll}\square \text { (a) } 99204 & \text { Comprehensive } \\ \square \text { (b) } 99203 & \text { Detailed } \\ \square \text { (c) } 99202 & \text { Expanded }\end{array}$

Established Patient

\begin{tabular}{ll}
$\square$ (g) 99215 & Complex \\
\hline (h) 99214 & Limited \\
\hline (i) 99213 & Expanded
\end{tabular}




$\begin{array}{llll}\square \text { (d) } 99201 & \text { Problem solving } & \square \text { (j) } 99212 & \text { Problem Solving } \\ \square \text { (e) } 99371 & \text { Telephone Conference } & \square \text { (k) } 99211 & \text { Minimal } \\ \square \text { (f) } 99071 & \text { Education Supplies } & \square \text { (l) } 99080 & \text { Outcome letter }\end{array}$

PPO

New Patient
(a) $99204 \quad$ Comprehensive
(b) $99203 \quad$ Detailed
(c) $99202 \quad$ Expanded
(d) $99201 \quad$ Problem solving
(e) 99371 Telephone Conference
(f) $99071 \quad$ Education Supplies

Established Patient

\begin{tabular}{|ll}
\hline$\square$ (g) 99215 & Complex \\
\hline$\square$ (h) 99214 & Limited \\
$\square$ (i) 99213 & Expanded \\
$\square$ (j) 99212 & Problem Solving \\
\hline$\square$ (k) 99211 & Minimal \\
$\square$ (l) 99080 & Outcome letter
\end{tabular}

IDM

New Patient
(a) 99204
Comprehensive
(b) 99203
Detailed
(c) 99202
Expanded
(d) 99201
Problem solving
(e) 99371
Telephone Conference
(f) 99071
Education Supplies

Established Patient

\begin{tabular}{|ll}
\hline$\square$ (g) 99215 & Complex \\
\hline$\square$ (h) 99214 & Limited \\
$\square$ (i) 99213 & Expanded \\
$\square$ (j) 99212 & Problem Solving \\
\hline$\square$ (k) 99211 & Minimal \\
$\square$ (l) 99080 & Outcome letter
\end{tabular}

CARE

New Patient
(a) 99204
Comprehensive
(b) 99203
Detailed
(c) 99202
Expanded
(d) 99201
Problem solving
(e) 99371
Telephone Conference
(f) 99071
Education Supplies

Established Patient

\begin{tabular}{|ll}
\hline (g) 99215 & Complex \\
\hline$\square$ (h) 99214 & Limited \\
$\square$ (i) 99213 & Expanded \\
$\square$ (j) 99212 & Problem Solving \\
\hline$\square$ (k) 99211 & Minimal \\
$\square$ (l) 99080 & Outcome letter
\end{tabular}

CAID

New Patient

\begin{tabular}{ll}
\hline$\square$ (a) 99204 & Comprehensive \\
$\square$ (b) 99203 & Detailed \\
$\square$ (c) 99202 & Expanded \\
$\square$ (d) 99201 & Problem solving \\
\hline (e) 99371 & Telephone Conference \\
$\square$ (f) 99071 & Education Supplies
\end{tabular}

Established Patient

\begin{tabular}{ll}
\hline$\square$ (g) 99215 & Complex \\
\hline (h) 99214 & Limited \\
\hline$\square$ (i) 99213 & Expanded \\
$\square$ (j) 99212 & Problem Solving \\
\hline$\square$ (k) 99211 & Minimal \\
$\square$ (l) 99080 & Outcome letter
\end{tabular}

12(a) Is a corresponding description necessary with the CPT?
$\square$ (a) $\mathrm{Y}$
(b) $\mathrm{N}$

If yes, check: 
HMO

$\square$ (c) Medical Nutrition Therapy

(d) Disease-Management Skills and Training

(e) Nutrition Assessment (initial, $\mathrm{f} / \mathrm{u}$ )

(f) Nutrition Counseling (initial, $\mathrm{f} / \mathrm{u}$ )

(g) Other

PPO

$\square$ (c) Medical Nutrition Therapy

(d) Disease-Management Skills and Training

(e) Nutrition Assessment (initial, f/u)

(f) Nutrition Counseling (initial, $\mathrm{f} / \mathrm{u}$ )

(g) Other

IDM

(c) Medical Nutrition Therapy

(d) Disease-Management Skills and Training

(e) Nutrition Assessment (initial, f/u)

(f) Nutrition Counseling (initial, $\mathrm{f} / \mathrm{u}$ )

(g) Other

\section{CARE}

$\square$ (c) Medical Nutrition Therapy

(d) Disease-Management Skills and Training

(e) Nutrition Assessment (initial, f/u)

(f) Nutrition Counseling (initial, $\mathrm{f} / \mathrm{u}$ )

(g) Other

\section{CAID}

(c) Medical Nutrition Therapy

(d) Disease-Management Skills and Training

(e) Nutrition Assessment (initial, f/u)

(f) Nutrition Counseling (initial, $\mathrm{f} / \mathrm{u}$ )

(g) Other

13) Would a medical necessity letter help in the case-by-case decision to reimburse for MNT?
HMO $\square$ (a) Y
PPO
(a) $Y$
IND
(a) $Y$
CARE
(a) $\mathrm{Y}$
CAID
(a) $\mathrm{Y}$

$\square$ (b) $\mathrm{N}$

(b) $\mathrm{N}$

(b) $\mathrm{N}$

(b) $\mathrm{N}$

(b) $\mathrm{N}$ 
13(a) Would you accept a medical necessity letter with a Physician's diagnosis (ICD-9) and a Registered Dietitian's signature
HMO $\square$ (a) Y
PPO $\square$ (a) Y
IND $\square$ (a) $Y$
CARE $\square$ (a) $\mathrm{Y}$
CAID $\square$ (a) $\mathrm{Y}$
$\square$ (b) $\mathrm{N}$
(b) $\mathrm{N}$
(b) $\mathrm{N}$
(b) $\mathrm{N}$
(b) $\mathrm{N}$

13(b) Registered Dietitian's signature with Lic.or, M.S.or PhD help?

$\begin{array}{ll}\text { HMO } \square \text { (a) Y } & \square \text { (b) N } \\ \text { PPO } \square \text { (a) Y } & \square \text { (b) N } \\ \text { IND } \square \text { (a) Y } & \square \text { (b) N } \\ \text { CARE } \square \text { (a) Y } & \square \text { (b) N } \\ \text { CAID } \square \text { (a) Y } & \square \text { (b) N }\end{array}$

14) Do you use outcome documentation such as cost benefit analysis (CBA), with case studies or practice guidelines, in the decision to reimburse (policy, case by case) for MNT?
HMO $\square$ (a) Y
PPO
(a) $\mathrm{Y}$
IND
(a) $\mathrm{Y}$
CARE
(a) $\mathrm{Y}$
CAID $\square$ (a) Y
\begin{tabular}{|l}
$\square$ (b) N \\
\hline (b) $N$ \\
$\square$ (b) $N$ \\
\hline (b) N \\
$\square$ (b) N
\end{tabular}

DEFINITION: Cost benefits analysis is an umbrella term that evaluates outcomes in terms of cost savings or effectiveness of Medical Nutrition Therapy. EXAMPLE a coronary heart disease program cost $\$ 800$ to operate and produces savings in medical cost of $\$ 2400$ with 3 or $4 \mathrm{RD}$ visits of 50 minutes each over 7 weeks created lower blood cholesterol levels and money saved due to a reduction in lipid medication.

15) (If no), Would you be interested in using CBA, case studies and/or practice guidelines, that show how nutrition services benefit your members and decrease costs to your company in your policy decision making for MNT reimbursement?
$\mathrm{HMO}$
(a) $\mathrm{Y}$
PPO
(a) $\mathrm{Y}$
(b) $\mathrm{N}$
IND
(a) $\mathrm{Y}$
(b) $\mathrm{N}$
CARE
(a) $\mathrm{Y}$
(b) $\mathrm{N}$
CAID
(a) $\mathrm{Y}$
(b) $\mathrm{N}$
(b) $\mathrm{N}$

Your input may provide information needed to allow RDs and insurance companies effective communication to allow MNT coverage for the necessary patients. 


\title{
APPENDIX B
}

\section{Fax Cover Letter}

\author{
KATHERINE CABRERA, RD LD. \\ HOME ADDRESS: \\ $400 \mathrm{NW} 202 \mathrm{WAY}$ \\ PEMBROKE PINES, FL 33029
}

FACSIMILE TRANSMITTAL SHEET

\begin{tabular}{lc}
\hline \hline TO: & FROM: \\
Ray Mummery, M.D. & Katherine Cabrera \\
\hline COMPANY: & DATE: \\
Dimension Health Inc. & $4 / 17 / 2002$ \\
\hline FAX NUMBER: & TOTAL NO. OF PAGES INCLUDING COVER: \\
1(305) 818-8814 Att: Dori & 1 \\
\hline PHONE NUMBER: & SENDER'S FAX NUMBER: \\
& (305) 362-1441 \\
\hline RE: & SENDER'S PHONE NUMBER: \\
Reminder for MNT survey & (954) 430-8985 \\
\hline \hline
\end{tabular}

NOTES/COMMENTS

Dear Dr. Mummery,

I am sending you a survey regarding outpatient Medical Nutrition Therapy

reimbursement criteria for your company in the State of Florida. I appreciate you taking time out of your busy schedule to complete the survey for my thesis. Again, thank you for your time and may the results of this survey help your company and customers in the future. Please return as soon as possible. Return FAX \# 1 (305) 362-1441.

Sincerely,

Katherine Cabrera (Graduate Student, Florida International University) 


\section{APPENDIX B (Continued)}

Fax Questionnaire

\section{TELEPHONE QUESTIONNAIRE}

Hello, I am a graduate student from Florida International University (FIU) working on my thesis. I am surveying insurance companies to collect information on criteria for outpatient medical nutrition therapy (nutrition services) reimbursement. The results will be described in overall averages for the thesis.

Please fill in the below information. Use one survey for each plan type. Check appropriate box.

Company Name:

Date (MM/DD/YYYY):

1) Your insurance company is a (an):
$\square$ (a) HMO
(b) PPO
(c) INDEM

2) Can you make decisions regarding claims for Medical Nutrition Therapy (MNT)? $\square$ (a) Y $\square$ (b) N

3) What is your professional title:

4) Does your company have a written policy on reimbursement for MNT?

$\square$ (a) Y (b) $\mathrm{N}$

If yes, can the policy be mailed or faxed to me (305)362-1441? $\square$ (c) Y

5) Do you reimburse for outpatient MNT case by case?
$\square$ (a) Y
(b) $\mathrm{N}$

6) If no, what department or person handles claims?

(MCO)

What department handles pre-authorizations? (or)

(INDEMNITY)

What department handles Claims?

7) Who reviews the cases. Title:

If 4 and 5 are NO (company does not reimburse) then skip to question \# 13. 
8) Is your criterion for reimbursement disease-state specific?
(a) $\mathrm{Y}$
(b) $\mathrm{N}$

9) If yes, which disease-state:

Aids

Cardiac Diseases (Htn,Hyperlipidemia,Cad)

Diabetes (Type I \& Ii Gestation)

Eating Disorders (Anorexia,Bulimia,Binge Eating,)

Morbid Obesity

Failure To Thrive (Peds)

High Risk Pregnancy

Renal Disease (Acute \& Chronic)

Inborn Error of Metabolism (KU)
IC9 Code

(a)

(b)

(g)

(h)

(i)

(j)
Max. Benefit Allowance

(k)

(m)

(n)

(o)

(p)

(q)

(r)

(s)

10) What CPT codes does your company accept for MNT?

Examples: Georgia Department of Medical Assistance, admin. Medicaid, two CPT for Licensed Dietitians: 99203 , 99213

North Dakota Blue Cross Blue Shield 99201, 99202,99211, 99212)

New Patient

$\square$ (a) 99204

(b) 99203

(c) 99202

(d) 99201

(e) 99371

(f) 99071
Comprehensive

Detailed

Expanded

Problem solving

Telephone Conference

Education Supplies
Established Patient

\begin{tabular}{ll}
\hline$\square$ (g) 99215 & Complex \\
$\square$ (h) 99214 & Limited \\
$\square$ (i) 99213 & Expanded \\
$\square$ (j) 99212 & Problem Solving \\
$\square$ (k) 99211 & Minimal \\
$\square$ (l) 99080 & Outcome letter
\end{tabular}

11) Is a corresponding description necessary?

$\square$ (a) Y

(b) $\mathrm{N}$

If yes, check:

(c) Medical Nutrition Therapy

(d) Disease-Management Skills and Training

(e) Nutrition Assessment (initial, $\mathrm{f} / \mathrm{u}$ )

(f) Nutrition Counseling (initial, $f / u$ )

(g) Other 
12) Would a medical necessity letter help in the case-by-case decision to reimburse for MNT?
$\square$ (a) Y
$\square$ (b) $N$

If Yes:

Would you accept a medical necessity letter with a:

$\square$ (c) Physician's diagnosis (ICD-9) and a Registered Dietitian's signature?

(d) Registered Dietitian's signature with Lic.or, M.S.or.PhD help?

$\square(\mathrm{c}) \mathrm{Y}$

$\square(\mathrm{d}) \mathrm{N}$

13) Do you use outcome documentation such as cost benefit analysis (CBA), with case studies or practice guidelines, in the decision to reimburse (policy, case by case) for MNT?
(a) $\mathrm{Y}$
(b) $\mathrm{N}$

(Cost benefits analysis evaluates outcomes in terms of cost saving of Medical Nutrition Therapy. The outcome is expressed in monetary terms, which allows for comparison to other medical treatment. Example: a diabetes program cost $\$ 800$ to operate and produces savings in medical cost of $\$ 2400$. Cost effectiveness analysis is an outcome expressed in units per dollar per life saved.)

14) (If no), Would you be interested in using CBA, case studies and/or practice guidelines, that show how nutrition services help with the quality of life for your members and decreases costs to your company in your policy decision making for MNT reimbursement? $\square$ C Y $\square(\mathrm{d}) \mathrm{N}$

Thank you for your time.

Your input will aid in the research for MNT third party reimbursement. 